\title{
Development of an intertidal foraminifera training set for the North Sea and an assessment of its application for Holocene sea-level reconstructions
}

\author{
Graham Rush ${ }^{\mathrm{a}, *}$, Patrick McDarby ${ }^{\mathrm{a}}$, Robin Edwards ${ }^{\mathrm{b}}$, Yvonne Milker $^{\mathrm{c}}$, Ed Garrett $^{\mathrm{a}}$, Roland Gehrels ${ }^{\mathrm{a}}$ \\ ${ }^{a}$ Department of Environment and Geography, University of York, YO10 5NG, UK \\ ${ }^{b}$ School of Natural Sciences, Trinity College Dublin, Ireland \\ ${ }^{c}$ Center for Earth System Research and Sustainability, Institute for Geology, University of Hamburg, Germany
}

\begin{abstract}
Regional datasets of the vertical distribution of intertidal foraminifera are useful to reconstruct Holocene sea-level changes from fossil foraminifera in estuaries and salt marshes. In this paper, we present a new foraminiferal dataset from the Ythan Estuary (Scotland) and combine it with data from eight other coastal sites from England, Denmark and Germany to produce a regional modern training set for the North Sea. We recognise a correlation between foraminifera and tidal elevation which makes the foraminifera suitable as sea-level indicators. We subdivide the data into subregional training sets and develop WA and WAPLS transfer functions. Applying a variety of statistical methods, including detrended canonical analysis, cross-validation by bootstrapping and leave-one-site-out, and the modern analogue technique, we establish the most appropriate transfer function from which to reconstruct early Holocene sea-level changes in a sediment core from the western North Sea coast. Results show that the subregional England/Scotland training set provides the most appropriate sea-level reconstructions, with decimetre-scale uncertainties. The techniques we use in this study, that consider both the modern and fossil assemblages to determine the best training set and transfer function, are suggested as a template for the development of regional transfer functions based on foraminifera and other intertidal microfossils.
\end{abstract}

Keywords: Sea level, Transfer function, Foraminifera, Salt marsh

\section{Highlights}

- New foraminifera modern training set for the Ythan Estuary, east Scotland.

- Synthesis of North Sea foraminifera data for sealevel reconstructions.

- Template for determining the most effective regional transfer function.

\section{Introduction}

Foraminifera have long been recognised as accurate and precise sea-level indicators in Holocene intertidal deposits (Scott and Medioli, 1978). This is because foraminiferal assemblages form in narrow vertical zones across the intertidal zone as a result of variations

\footnotetext{
${ }^{*}$ Corresponding author

Email address: G. Rush@leeds .ac.uk (Graham Rush)
}

14 in tidal submergence. The correlation with elevation rel5 ative to the tidal frame provides a tool to reconstruct sealevel changes from fossil intertidal foraminifera preserved in sediment cores (Gehrels, 2000). When the relationship between foraminifera and elevation in the modern environment is quantified, regression methods can be applied to develop predictive transfer functions that are capable of reconstructing sea-level changes from fossil foraminiferal assemblages in subsurface intertidal deposits. Relative sea-level reconstructions based on foraminifera in salt-marsh deposits have been established in many temperate coastal regions with high vertical precision, often quoted as sub-decimetre (e.g. Gehrels et al., 2004; Horton et al., 2009; Hawkes et al., 2010; Engelhart et al., 2011; Wright et al., 2011; Barnett et al., 2016), leading salt marshes to be labelled 'geological tide gauges' (Barlow et al., 2013). Consistency is used as an informal indicator and the assumption of uniformitarianism is applied, since it is not possible to assess the accuracy of palaeo reconstructions prior to pre-instrumental records. 
Many studies use foraminiferal assemblages in mod- 87 ern samples from a proximal site, collectively known as a training set, to develop local transfer functions that are then applied to reconstruct sea level based on fossil assemblages from a core (e.g. Gehrels et al., 2004, 2005). This method relies on the assumption that the assemblages in the modern environment are an accurate analogue for the past environment and fossil foraminifera preserved in the core. In the absence of appropriate analogues in local training sets, and therefore a likely non-conformity of environmental conditions, a regional training set developed from multiple sites may be more appropriate (Watcham et al., 2013; Barlow et al., 2013). A regional dataset is a collection of training sets from 100 multiple sites along a stretch of coastline, although the ${ }_{101}$ size of the region is not defined (Barlow et al., 2013). 102 Regional foraminifera training sets have been devel- ${ }_{103}$ oped for regions such as the UK (Horton et al., 1999), 104 southwest Europe (Leorri et al., 2011), Oregon, west- 105 ern USA (Hawkes et al., 2010) and the eastern coast 106 of the USA (Wright et al., 2011; Kemp et al., 2012). ${ }_{107}$ The method has been used to produce continuous sealevel records for the late Holocene (e.g. Hawkes et al., 2010; Engelhart et al., 2011) and the early Holocene using foraminifera (Horton et al., 1999) and diatoms (Lawrence et al., 2016). Barlow et al. (2013) discuss the relative benefit of local and regional approaches, but in general a regional training set that comprises sites where faunal assemblages are responding to tidal inundation in a similar manner increases natural variability and therefore the potential of providing an analogous environment.

For early and middle Holocene sea-level reconstructions developed from intertidal microfossils, the likelihood that environmental conditions and/or the realised niches of taxa at a single site have remained constant may be small. For example, Edwards and Horton (2000) 120 found that of 26 fossil assemblages from cored inter- 121 tidal sediments in the south of England, 10 were unlike 122 any other modern surface assemblage. A lack of mod- 123 ern analogues requires the inclusion of additional sites 124 in to a larger training set. Assemblages from multiple 125 sites are more likely to capture a wider range of envi- 126 ronmental conditions with a greater chance of provid- ${ }_{127}$ ing a suitable modern analogue (Legendre and Fortin, 128 1989; Juggins and Birks, 2012), with the caveat that the ${ }_{129}$ precision of the prediction may be reduced. For exam- 130 ple, Lawrence et al. (2016) applied a regional diatom 131 transfer function to generate an early Holocene sea-level 132 reconstruction in southwest Scotland based on samples ${ }_{133}$ from nine sites on the west coast of Scotland. Yet a ${ }_{134}$ key taxon found in the fossil record had become extinct 135 in the area and a further site from the English North Sea coast was included to provide the missing analogue. This reduced the mean precision of the sea-level reconstruction which was calculated at $\pm 56 \mathrm{~cm}$ (Lawrence et al., 2016). These examples highlight that whilst generally reducing precision, regional transfer functions are generally required to ensure reconstructions of early Holocene sea-level changes based on microfossils are more likely to be accurate. We deem a reconstruction to be accurate if it is consistent with others using different training sets and models where foraminifera show a similar inter-site relationship with tidal inundation.

In this paper we compile a new regional training set of intertidal foraminifera for the North Sea basin. The training set includes nine sites from the eastern (England and Scotland) and western (Denmark and Germany) coasts of the North Sea. Data from eight sites have been previously published and we add to this by presenting a new local dataset for a site on the east coast of Scotland, the Ythan Estuary. The aims of this paper are:

1. to study the relationship with elevation relative to sea level of the modern foraminifera in the Ythan Estuary and the regional composite training set, known forthwith as the North Sea training set, and hence its suitability for reconstructing sea-level changes.

2. to assess the best choice of transfer function between regional, sub-regional and local training sets, to reconstruct relative sea-level change from an early Holocene sediment core and provide a template for decision making in similar studies.

\section{Materials and Methods}

\subsection{Ythan Estuary training set development}

The Ythan Estuary consists of mudflats, salt marshes and freshwater marshes (Fig. 1). The River Ythan is tidal up to $11 \mathrm{~km}$ from the mouth of the estuary (Stapleton and Pethick, 1996) and the intertidal area is approximately $1.85 \mathrm{~km}^{2}$ of which $0.13 \mathrm{~km}^{2}$ is intact salt marsh. The mean tidal range at the mouth of the estuary is $2.48 \mathrm{~m}$ as calculated by taking a weighted average of two nearby tidal gauge stations at Aberdeen (57 $8.64^{\prime}$ $\left.\mathrm{N}, 2^{\circ} 4.82^{\prime} \mathrm{W}\right)$ and Peterhead (57²9.84' N, -2 $13.69^{\prime}$ $\mathrm{W}$ ), $18 \mathrm{~km}$ and $15 \mathrm{~km}$ away respectively (UK Hydrographic Office, 2016). To the north and west, the estuary is mostly bounded by arable farmland. However, in the 'Sleek of Tarty' area adjacent to the mouth of the Tarty Burn tributary (see Fig. 1) the salt marsh extends into a freshwater marsh and woodland. In this area the salt 

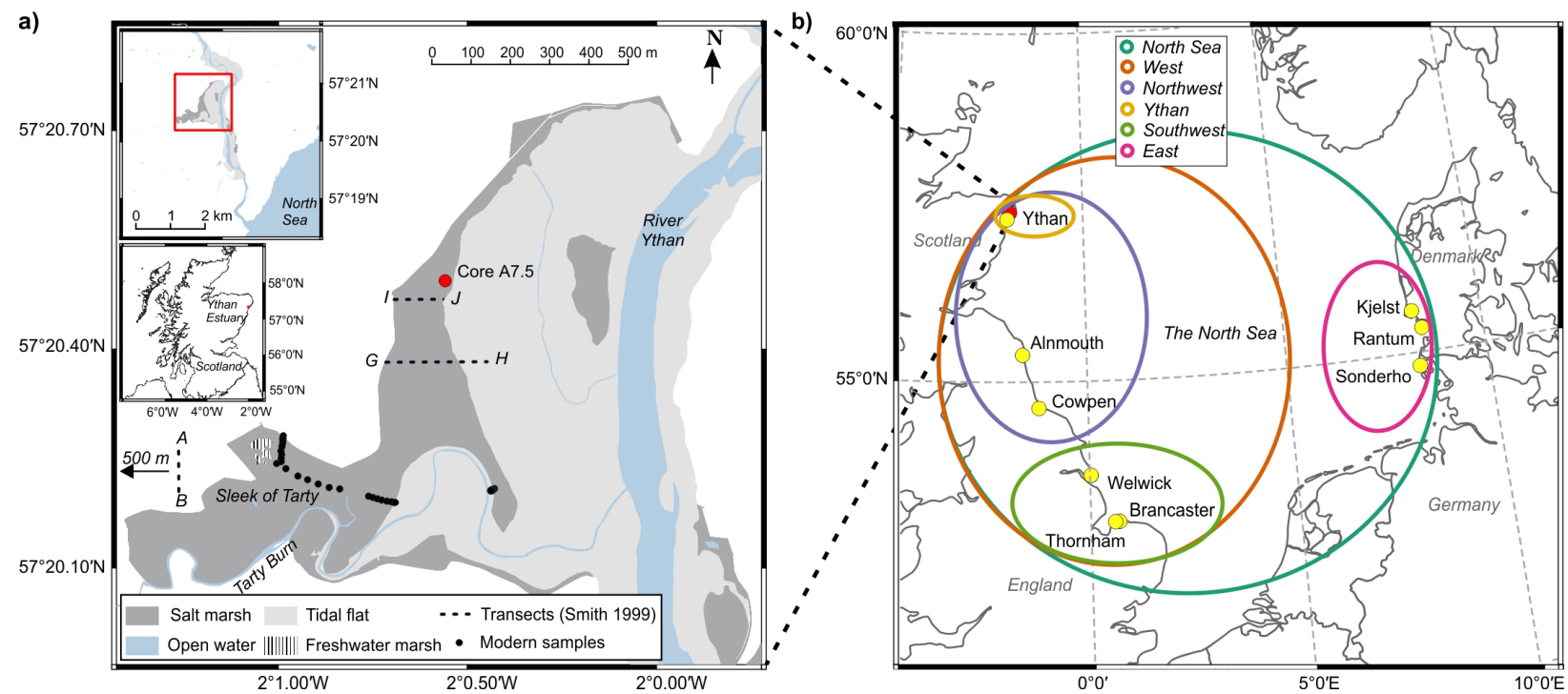

Figure 1: Map of the Ythan Estuary and North Sea sites. a) The Ythan Estuary showing the transects of modern samples, the transects from Smith et al. (1999) shown in Fig. 6a and the location of core A7.5 described in the text and Fig. 6b. b) Map of modern foraminifera sites (yellow markers) that make up the training sets. Red marker indicates the site of the core used in the reconstruction. Coloured ellipses indicate groupings of sites for regional and subregional datasets. The names for each region or subregion correspond to the main text.

marsh is characteristically undulating with many well 165 defined ponds and creeks. The lower salt marsh gener- 166 ally terminates at a small tidally cut cliff, although oc- ${ }_{167}$ casionally grades into the mudflat.

We established a local benchmark using a Trimble R6 169 model 3 DGPS with a vertical uncertainty of $0.006 \mathrm{~m} .170$ The benchmark was tied to two local Ordnance Survey 171 benchmarks to provide elevation measurements relative 172 to the UK national vertical geodetic ordnance datum ${ }^{173}$ (OD). Transects were designed to capture the elevation 174 gradient from the highest occurrence of foraminifera 175 (HoF) to mean tide level (MTL) and included a fresh- 176 water reed bed, high, middle and low salt marsh zones 177 and mudflat. Sampling was timed to coincide with a 178 large spring tide to maintain standardisation with other 179 studies and to allow sampling at lower elevations (e.g. 180 Avnaim-Katav et al., 2017). Sampling sites were established at c. $5 \mathrm{~cm}$ elevation intervals along two tran- 181 sects using a Trimble M1 DR2 total station. Standardised surface samples of $10 \mathrm{~cm}^{2}$ by $1 \mathrm{~cm}$ deep were collected (e.g. Gehrels, 2000). After collection samples were stored at $4{ }^{\circ} \mathrm{C}$ before processing.

Preparations of foraminifera samples followed stan- 186 dard laboratory procedures (Gehrels, 2002). The $63-187$ $500 \mu \mathrm{m}$ fraction of a $5 \mathrm{cc}$ subsample was wet sieved ${ }_{188}$ and stored in a Rose Bengal and ethanol solution within 189 seven days of collection to enable identification of liv- 190 ing and dead foraminifera (Murray and Bowser, 2000). 191 Tests containing stained protoplasm within the last few 192 chambers were assumed to be living and only the dead foraminiferal taxa were investigated to avoid seasonal bias (Culver and Horton, 2005) and provide the most representative analogue for material found in fossil records (Horton et al., 1999; Horton and Edwards, 2006; Berkeley et al., 2007; Kemp et al., 2009). Samples were split using a wet splitter (Scott and Hermelin, 1993) and picked and counted until a target of at least 200 individuals was met in even $1 / 8$ splits. If this number was not achieved the full sample was counted. Individuals were identified with reference to the taxonomy of de Rijk (1995); Wright et al. (2011); Edwards and Wright (2015); Müller-Navarra et al. (2017); Hayward et al. (2020). A total of 37 samples were counted and individual taxa expressed as their percentage relative abundance of the sample.

\subsection{Regional training set compilation}

Existing modern salt-marsh foraminifera training sets, collected from around the North Sea, include Alnmouth, Brancaster, Cowpen, Thornham and Welwick (Horton and Edwards, 2006), Brancaster (Gehrels et al., 2001), Kjelst (Gehrels and Newman, 2004), Rantum, Soønderho (Müller-Navarra et al., 2017) and Tümlau (Müller-Navarra et al., 2016) (see Fig. 1). All of the data was included except Tümlau, because of human interference that makes it unsuitable for sea-level reconstructions (Müller-Navarra et al., 2016), and two Alnmouth transects because of our doubts over the accuracy 
of the elevation measurements. Tidal datums were taken 242 from the original publications and the tidal range was 243 modelled for each site using the TPXO8-ATLAS global 244 model of ocean tides (Egbert and Erofeeva, 2010). The 245 data are summarised in Table 1 and throughout the text. 246

In order for the local training sets to be incorpo- 247 rated into a regional model, taxonomy was standard- 248 ised using the World Register of Marine Species (Hay- 249 ward et al., 2020) (Supplementary info Table 1) and 250 the sample elevation was standardised using a standard- 251 ised water level index (SWLI) which accounts for differences in tidal range between the sites (Zong and Horton, 1999; Gehrels, 2000). The lowest common phylogenic level was applied which resulted in some taxa being grouped at genus level. The only common environmental variable across all sites was elevation relative to a local datum. While inundation frequency is a more direct ecological parameter (Gehrels, 2000; Gehrels et al., 2001; Müller-Navarra et al., 2017), elevation is a linear approximation that is widely used and is applied here in the absence of inundation information across ${ }^{252}$ all sites. Generally MTL and mean high water spring 253 tide (MHWS) or mean higher high water (MHHW) have 254 been used for standardisation between sites with dif- 255 ferent tidal ranges in sea-level studies; however, trans- 256 fer functions are sensitive to the choice of tidal da- 257 tum (Woodroffe and Long, 2010; Wright et al., 2011). 258 Woodroffe and Long (2010) demonstrated that highest 259 astronomical tide (HAT) causes less distortion in the 260 upper tidal range, a key locale in foraminifera recon- 261 structions (Gehrels et al., 2004). Wright et al. (2011) 262 investigated this cross site standardisation further and 263 concluded that the well-established ecological relation- 264 ship between HoF and the upper limit of marine influ- 265 ence is more effective yet. However, sampling up to the 266 elevation of HoF is only definitively reached at two of 267 the sites (Brancaster and Ythan) and we therefore use 268 the highest common datum, HAT, in the standard SWLI 269 equation (Eq. 1) (Horton et al., 1999)

$$
S W L I_{n}=\frac{100\left(h_{n}-M T L_{s}\right)}{H A T_{s}-M T L_{s}}+100
$$

such that where $S W L I_{n}$ is the standardised water level ${ }_{274}$ index of the sample $(n), h_{n}$ is the height of the sample in 275 the local datum, $M T L_{s}$ and $H A T_{S}$ are the mean tide level 276 and highest astronomical tide of the site $(s)$ in the local 277 datum.

The full regional training set, known forthwith as the 279 North Sea training set, was sub-divided in order to test 280 the effect on model performance of training set size and 281 tidal range, that naturally coincides with geographic re- 282 gions (Fig. 1b) owing to the North Sea tidal set up.
The data was screened such that samples were retained if total counts were $>75$ in order to be able to reconstruct sea-level change at a decimetre- and decadalscale (Kemp et al., 2020). The nine sites provided a total of 265 samples of foraminifera assemblages from 52 different taxa. The screening of the raw data of each training set resulted in between 17 and $35 \%$ (Northwest and Ythan respectively) of samples being removed. The large variation in samples being removed is largely due to zero counts being included in some sites.

Table 1: Summary of intertidal sites included in the regional training sets. Geomorphic classifications are based on Allen (2000). The number of taxa and samples are given for the raw data and after screening.

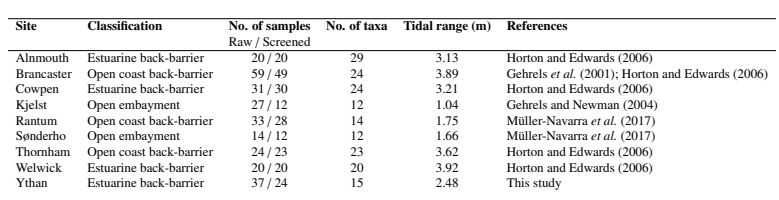

\subsection{Transfer functions and data analysis}

Detrended canonical correspondence analysis (DCCA) (Hill and Gauch, 1980) was applied using the software CANOCO version 5.1 (ter Braak and Smilauer, 2012) to test whether the taxa response is linear or unimodal along the elevation gradient. All datasets had a DCCA axis gradient length greater than two standard deviations, generally accepted as being the threshold, such that unimodal statistical models are appropriate for exploration of the training sets (Birks, 1995). We therefore developed unimodal transfer functions for the six training sets using two different techniques: weighted averaging with classical deshrinking (WA) (ter Braak and Barendregt, 1986) and weighted averaging with partial least square regression (WAPLS) (ter Braak and Juggins, 1993).

WA based transfer functions take the average of all the optima of all the taxa weighted such that those with greater abundances are given more prominence. This causes the vertical range to be compressed and thus a 'deshrinking' correction is necessary. Inverse deshrinking, equivalent to WAPLS component 1 , is more suitable for reconstructions close to the middle of the environmental gradient, whilst classical deshrinking is more suitable for reconstructions close to the limits of the gradient (Juggins and Birks, 2012; Kemp and Telford, 2015). We aim to capture the maximum environmental gradient and we therefore favour the use of the classical method for the WA transfer functions.

WAPLS based transfer functions (components 2 and higher) exploit correlations that remain in the residuals after fitting SWLIs that are not taken into account in 
WA by adjusting taxa optima (Juggins and Birks, 2012; 336 Kemp and Telford, 2015). Each extra component can be ${ }_{337}$ seen as adding extra, hypothetical, environmental vari- 338 ables. WAPLS generally outperforms WA because; 1) 339 'edge effects' that affect WA where optima are overes- 340 timated at the low end and underestimated at the high ${ }_{341}$ end (Mohler, 1983) can be reduced or eliminated by 342 WAPLS; and/or 2) because in reality the composition of taxa assemblages is influenced by additional factors other than elevation and WAPLS can exploit the resultant structured pattern in the residuals after WA; and/or 3 ) the fit of outliers may be improved (Birks, 1995; Juggins and Birks, 2012). WAPLS is thus favoured in many sea-level studies (Barlow et al., 2013). We chose the best performing model with the fewest numbers of components, limited to three, following the rule of parsimony (Birks, 2012), only selecting successive components if a significant performance increase, based on the root mean squared error of prediction (RMSEP) and $R^{2}$ values (Birks, 1998), of $>5 \%$ is observed. These are from here on known as the WAPLS transfer functions with the number of components given as c (e.g WAPLS$c 1)$.

Locally weighted transfer functions (LW) can take advantage of both local and regional training sets by using a set number of closest analogues for each fossil sample as defined by Modern analogue technique (MAT) and predict the sea level using these (Kemp and Telford, 2015). We chose the 50 closest analogues (Birks, 2012) in the final training set and then dynamically developed a WAPLS transfer function for each fossil sample, given as LW-WAPLS.

To assess the best choice of transfer function for ${ }^{362}$ a sea-level reconstruction, we collected a core (A7.5) ${ }^{363}$ from the Ythan Estuary using a $50 \mathrm{~mm}$ Russian corer 364 at $57^{\circ} 20.49^{\prime} \mathrm{N}, 2^{\circ} 0.54^{\prime} \mathrm{W}$. The site was selected based ${ }^{365}$ on published stratigraphy by Smith et al. (1999) who 366 dated the peat at the base of a core at $5.19 \mathrm{~m}$ core depth ${ }^{367}$ to c. $8.5 \mathrm{ka}$ cal BP. This basal peat is overlain by salt- 368 marsh and mudflat deposits, and topped by a sand de- 369 posit that is attributed to the Storegga tsunami of c. 8.15370 ka cal BP (Dawson et al., 2011; Bondevik et al., 2012). 371 We took 1-cm-thick subsamples from the core at appro- 372 priate depths with respect to lithological and biological 373 changes in an iterative manner between the basal peat ${ }_{374}$ at $5.17 \mathrm{~m}$ and the base of the sand deposit at $2.28 \mathrm{~m} 375$ core depth. Thus the core spans a period in the early 376 Holocene that is of interest as it potentially includes 377 the sea-level rise associated with the drainage of glacial 378 lakes Agassiz and Ojibway at ca. $8.4 \mathrm{ka}$ cal BP (Bar- 379 ber et al., 1999; Li et al., 2012; Hijma and Cohen, 2010, 380 2019; Lawrence et al., 2016). A total of 24 samples 381 were prepared and foraminifera counted as described above.

The resultant WA, WAPLS and LW-WAPLS transfer functions were used to predict SWLIs from the core fossil foraminifera. This was converted to an indicative meaning in metres by reversing Eq. 2 using the following equation:

$$
I_{f}=\frac{\left(S W L I_{f}-100\right)\left(H A T_{b}-M T L_{b}\right)}{100}+M T L_{b}
$$

where $I_{f}$ is the indicative meaning of the fossil sample $\left(_{f}\right)$ in the local datum, $S W L I_{f}$ is the predicted SWLI of the fossil sample $(f), H A T_{b}$ and $M T L_{b}$ are the highest astronomical tide and mean tide level of the site $(b)$ in the local datum. The transfer functions also produce prediction sample specific errors ( $S S E$ ) for the fossil samples that is converted in the same manner and used as the range of the reconstructions (range $=I_{f} \pm S S E$ ).

To assess training set and transfer function performance and decide on the most suitable to use for our core reconstruction, we conducted qualitative and quantitative analyses in a step-wise manner. All analyses were carried out in $\mathrm{R}$ version 3.6.1 using the packages rioja (Juggins, 2017), vegan (Oksanen et al., 2019) and fpc (Hennig, 2019). We used the following methods:

1. Detrended Correspondence Analysis (DCA) with fossil samples passively projected to assess the samples and taxa groupings and relationships (Edwards and Wright, 2015).

2. Constrained correspondence analysis (CCA) to quantify the proportion of variance explained.

3. Cluster analysis using partitioning around medoids (PAM) with Euclidean distances (Kaufmann and Rousseeuw, 1990; Rousseeuw, 1987) to recognise clusters of modern and fossil foraminiferal assemblages. The highest average silhouette width was used to determine the appropriate number of partitions (Kemp et al., 2013) .

4. Modern analogue technique (MAT) using the minimum dissimilarity coefficient (MinDC) to measure the dissimilarity between fossil samples and the closest modern analogue using the commonly applied Chord-squared distance metric (Kemp and Telford, 2015). We applied the conservative method of defining 'good' and 'close' modern analogues for fossil samples as having a MinDC lower than the $5^{\text {th }}$ and $20^{\text {th }}$ percentiles respectively and samples with a larger MinDC defined as 'poor' (Watcham et al., 2013; Barlow et al., 2013). 
5. Transfer function performance statistics using ${ }_{431}$ bootstrapping (boot) and leave-one-site-out ${ }^{432}$ (LOSO) cross-validation to assess the quality of ${ }_{433}$ the transfer functions and the independence of ${ }^{434}$ samples (Telford and Birks, 2005; Payne et al., 435 2012; Kemp et al., 2013).

6. If using WAPLS with $>2$ components the pat- ${ }^{437}$ tern of taxa optima updates were analysed to assess 438 the effect of introducing more statistical complex- 439 ity that may distort reconstructions (Wright et al., 440 2011).

7. Ranges of the different core reconstructions were ${ }^{442}$ compared to evaluate the likely accuracy of each ${ }^{443}$ regional, subregional and local transfer function. $\quad{ }^{444}$

8. The statistical significance of the reconstructions ${ }^{445}$ was measured by comparing the reconstructions ${ }^{446}$ from the training sets against a set of 999 randomly ${ }^{447}$ generated data using redundancy analysis ordina- ${ }^{448}$ tion (Telford and Birks, 2011).

\section{Results and Discussion}

\subsection{Training set development}

\subsubsection{Ythan Estuary data}

Foraminifera occur in the Ythan Estuary from the ${ }^{456}$ lowest sampled point of just above MTL across the ele- ${ }_{457}$ vation gradient of the tidal zone to just above HAT. Both ${ }_{458}$ dead and living individuals were found up to an elevation of $2.45 \mathrm{~m}$ OD (SWLI = 202). A total of 15 taxa 459 were found although four had a maximum abundance 460 $<10 \%$. The majority of taxa show some relationship ${ }_{461}$ with elevation (see Fig. 2). Taxa elevation optima (the ${ }_{462}$ abundance weighted average of SWLI in all samples ${ }_{463}$ in which they occur (ter Braak and Barendregt, 1986)) 464 and tolerances (the abundance weighted standard devi- 465 ation (Birks et al., 1990)) following WA show that the 466 different taxa occupy a gradient of different elevations ${ }_{467}$ (Fig. 2c). The highest marsh samples, above MHWS ${ }_{468}$ at $1.96 \mathrm{~m}$ OD where tidal inundation is infrequent, are ${ }_{469}$ low in total foraminifera counts and hence only one was 470 retained following screening. In these samples Balti- 471 cammina pseudomacrescens appears in relatively high 472 abundance much like in the eastern North Sea marshes ${ }_{473}$ (Gehrels and Newman, 2004; Müller-Navarra et al., 474 2017). The salt-marsh samples are almost entirely com- 475 posed of agglutinated taxa. Entzia macrescens, also 476 commonly referred to as Jadammina macrescens, is the 477 most common salt-marsh taxon and is found in simi- 478 lar abundances across the marsh. Miliammina fusca is 479 found in greatest abundances in the lower marsh like 480 in many marshes globally (see Berkeley et al., 2007). 481
Cluster analysis (Fig. 2a) shows that the salt-marsh samples can be subdivided into three clusters that are also somewhat evident in the DCA plot (Fig. 2b). A low marsh cluster is formed with high abundance of Miliammina fusca, a mid-high marsh cluster with a mixture of agglutinated taxa and a final cluster with Haplophragmoides spp. found in unusually high abundances (> $75 \%$ ) compared to other UK salt marshes (Horton et al., 1999). There is a clear shift to assemblages dominated by calcareous species at $1.22 \mathrm{~m} \mathrm{OD}$ just below the transition from salt marsh to mudflat, along with occasional Trochammina ochracea and Haplophragmoides spp. PAM clustering displays two distinct clusters of these mudflat samples, one with Haynesina germanica most abundant and featuring high abundances of Buliminella elegantissima and Brizalina variabilis, and a second with few Buliminella elegantissima and Brizalina variabilis and dominated by Elphidium williamsoni, Trochammina ochracea and Haplophragmoides spp. Though usually found in the vegetated zone (Berkeley et al., 2007) Haplophragmoides spp. are also found on mudflats in the east of the North Sea (Müller-Navarra et al., 2017). CCA shows that $24.59 \%$ of the variance can be explained by elevation. The modern foraminifera surface distributions of the sampled tidal zone in the Ythan Estuary display a wellestablished relationship with elevation and are therefore suitable sea-level indicators.

\subsubsection{Compiled North Sea data}

The foraminifera of the eight previously published sites and the Ythan (see Table 1) combined in the regional North Sea data occur at elevations from 273 SWLI, well above HAT, to 70, below MTL (Fig. 3). The highest 14 samples (> 210 SWLI), well above HAT, are all from the sites in Denmark and Germany. This could be due to the wind-induced setup that occurs in these areas (Bartholdy et al., 2004; Pedersen et al., 2009), where tides $>3 \mathrm{~m}$ above HAT in Esbjerg have been recorded (Bartholdy et al., 2010). These samples are generally restricted to Balticammina pseudomacrescens and Entzia macrescens which are species able to survive despite infrequent flooding (Berkeley et al., 2007). Although micro tidal sites are generally desired because they provide higher precision reconstructions (Callard et al., 2011; Barlow et al., 2013; Edwards and Wright, 2015) they will be more influenced by this effect and hence the micro tidal range of the eastern sites (all < $1 \mathrm{~m}$ ) may be causing the extremely high SWLI values seen in these sites a phenomenon also seen in some sites in the US (Wright $e t$ al., 2011). The assemblages of the remaining salt-marsh samples are dominated by ag- 
(a)

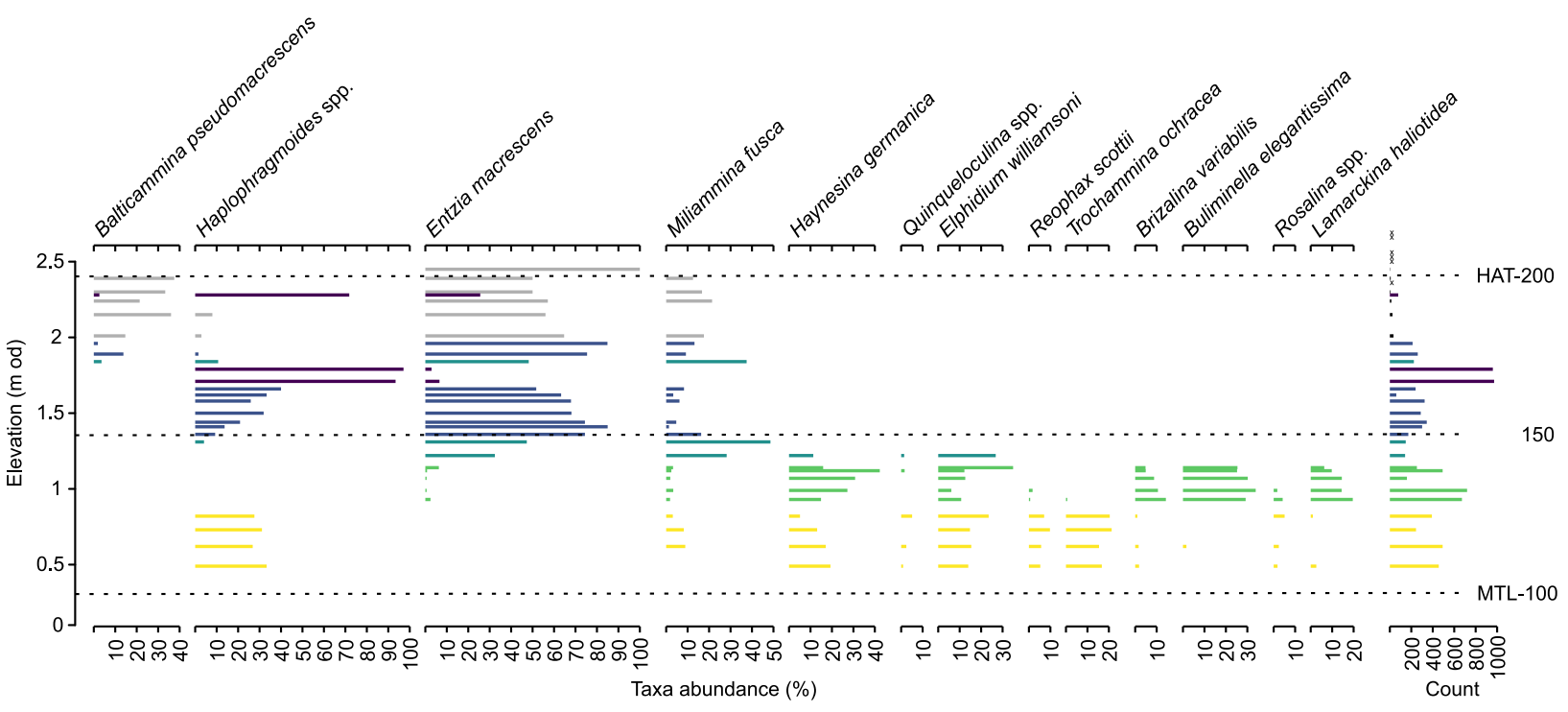

(b)

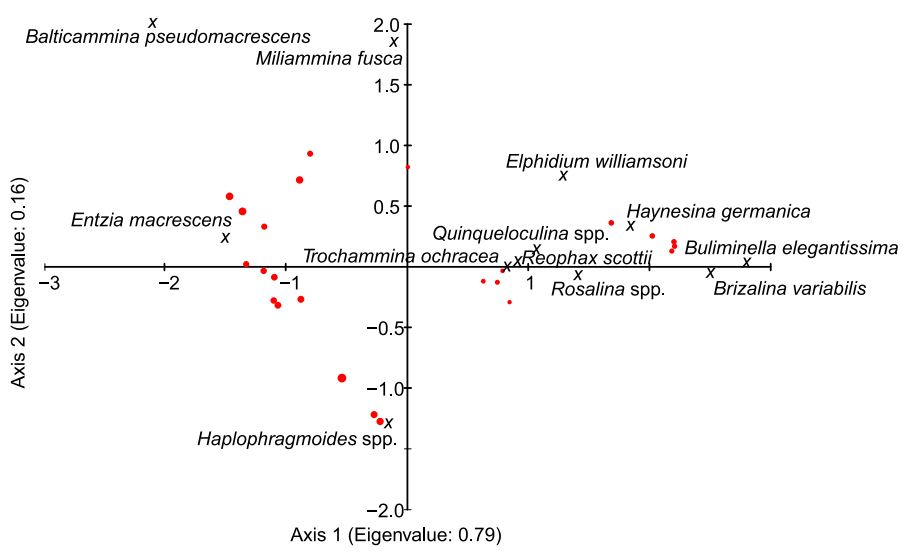

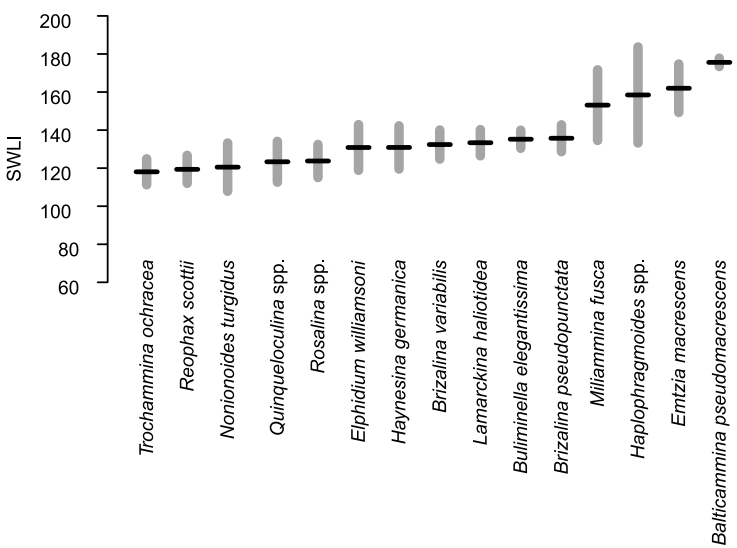

Figure 2: Summary diagrams of the modern foraminifera assemblages for the Ythan Estuary: a) Foraminifera abundances as percentages of the count of total dead specimens (given in the final column) against elevation. Only taxa with $>5 \%$ maximum abundance are shown. Grey bars denote samples that were excluded following screening and Xs mark where no foraminifera were found. The bars are coloured according to PAM clustering of the dataset (average silhoutte width $=0.53$ ). Dashed lines indicate tidal datums and SWLI values. b) Detrended correspondence analysis (DCA) of surface foraminifera assemblages showing samples in circles, sized according to SWLI, and taxa. c) Taxa tolerances (grey bar) and optima (black lines) of the Ythan Estuary foraminifera taxa following WA with classical deshrinking.

glutinated foraminifera. Entzia macrescens is abundant 492 across the marsh, as is Miliammina fusca although in ${ }_{493}$ lower abundances. Trochammina inflata appears mainly 494 restricted to the higher marsh, while Haplophragmoides 495 spp. become more prevalent in the middle-lower marsh 496 mainly at Rantum, Sønderho and Ythan. Calcareous 497 taxa become more abundant in the lower marsh, al- 498 though are found much higher particularly in eastern 499 marshes which may be due to the wind-induced setup 500 and/or high $\mathrm{pH}$ promoting better preservation (Müller- 501
Navarra et al., 2016). Relatively high abundances of Ammonia spp. are found at Brancaster and Thornham compared to the other sites, while Haynesina germanica is notably abundant at Welwick. Foraminifera were not sampled below 140 SWLI, approximately at the transition between the salt marsh and the mudflat, at Brancaster, Kjelst and Thornham. However, the assemblages from the sites that were sampled show a clear dominance of calcareous taxa. The taxa abundances appear to show a relationship with elevation across the training 
set, although it may be reduced at the eastern sites due ${ }_{554}$ to local conditions.

The relationship between taxa and elevation is con- 556 firmed by the cluster analysis (Figs. 3 and 4) and DCA 557 (Fig. 5). PAM clustering produces the highest average 558 silhouette width when samples are split into three clus- 559 ters, shown in Figs. 3 and 4. Cluster 1 mainly comprises 560 the mudflat samples (defined as SWLI approximately $<561$ 140) dominated by calcareous taxa from a mixture of 562 sites. Cluster 2 mainly comprise samples where Hap- 563 lophragmoides spp. are abundant as described above. 564 While Haplophragmoides spp. are not rare taxa and 565 are found at varying elevations relative to tidal inun- 566 dation in other marshes (e.g. Berkeley et al., 2007, for 567 a review), they are marked out in these samples by its 568 high abundance that cause high intra-cluster similarity ${ }_{569}$ and low dissimilarity with other samples. Finally, sam- 570 ples in cluster 3 contain the majority of salt-marsh sam- 571 ples. The majority of samples are dominated by Entzia 572 macrescens and encompass the full elevation range of 573 the salt marsh. A cluster of samples that are almost 574 entirely found above 170 SWLI and comprise Entzia 575 macrescens, Miliammina fusca and Trochammina in- 576 flata is identified from within cluster 3 if we add extra 577 clusters.

A feature of the data appears to be a small degree of 579 clustering by sites. This could be due to a lack of inde- 580 pendence of samples because of spatial auto-correlation 581 that may cause transfer function performance statis- 582 tics to be overly optimistic (Telford and Birks, 2005; 583 Payne et al., 2012), or that each site has unique con- 584 trols that could make a regional transfer function ei- 585 ther problematic or arguably more robust (Legendre and 586 Fortin, 1989). To investigate this further LOSO cross- 587 validation was applied and is discussed below. $\quad 588$

The DCA plots summarise the unconstrained rela- 589 tionship between samples, taxa and SWLI (Fig. 5). The 590 plot shows that the samples tend to align towards axis 1591 and appear somewhat correlated with SWLI with gen- 592 eral clustering of higher and lower SWLI samples. The 593 relationship is confirmed by CCA such that $7.13 \%$ of 594 the variance can be explained by elevation, and that the 595 ratio of the axis constrained by SWLI and the first un- 596 constrained axis is 1.04, indicating it is an important 597 variable in explaining taxa distributions (Kemp et al., 598 2013). A number of samples diverge from axis 1 in the 599 DCA plot and may therefore be influenced by secondary 600 variables. These samples are those described above, 601 where Haplophragmoides spp. are found at higher el- 602 evations. Although other environmentally variables are 603 generally correlated with elevation (i.e. salinity, $\mathrm{pH}$ ), it 604 is evident that other environmental variables are affect- 605 ing the taxa niches which is not unexpected considering the inclusion of multiple sites from differing environments and tidal ranges. The taxa-sample relationships shown in Fig. 5b confirm the effect of Haplophragmoides spp. and also notably how Balticammina pseudomacrescens drives the samples with the highest elevations. Collections of taxa are evident along axis 1, where agglutinated and calcareous taxa show a general partition. Some modern Ythan samples appear to be consistently distal from other sites and/or axis 1 suggesting they are providing assemblages with somewhat differing response to elevation. However, similarities with other samples from across the North Sea suggest comparable conditions may be occurring at a wide range of sites.

PAM and DCA analysis suggests that the foraminifera assemblages that make up the North Sea training set are appropriate as sea-level indicators. The agglutinated taxa appear particularly well suited, as observed by others, although may lack more definitive zonation (e.g. Horton et al., 1999; Gehrels, 2000; Gehrels et al., 2005; Horton and Edwards, 2006; Kemp et al., 2013; Barnett et al., 2016). Calcareous taxa are useful indicators of tidal flats in the data and hence useful for transfer functions where a wide environmental range may be sought. However, the lowest occurrence of some taxa is not sampled meaning the full range is not captured, which could be problematic for predicting the lowest range of some fossil samples and so these should be treated with an element of caution (Woodroffe, 2009). Calcareous taxa also occur across a wide elevation range in the region, which may impact the predictive ability of the transfer functions. This wide range may be due to in-wash resulting in allochthonous foraminifera (Murray, 2003; Horton and Murray, 2006). Some studies attempt to avoid this effect by either not sampling the tidal flat (e.g. Gehrels, 2000; Kemp et al., 2013)) and/or removing these so termed 'exotic' taxa (e.g. Horton and Edwards, 2006; Kemp et al., 2009; Leorri et al., 2011; Mills et al., 2013) resulting in better predictability in some cases. However, Mills et al. (2013) observe that performance does not improve in their Mersey training set and that this method does not preclude the mixing of lower marsh agglutinated foraminifera. We include all samples as our core includes a fossil mudflat environment and thus the lower samples are critical as well as providing a lower limit to some of the agglutinated marsh taxa (Wright et al., 2011). However, other cores that are limited to salt marsh environments may warrant investigation of the effect of removing lower elevation samples or taxa. 


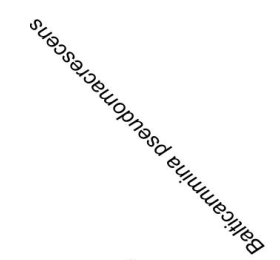

| 1 11111 1 11 11 11111 11

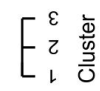

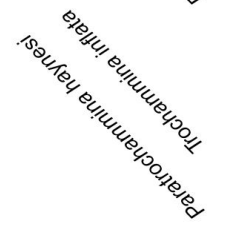

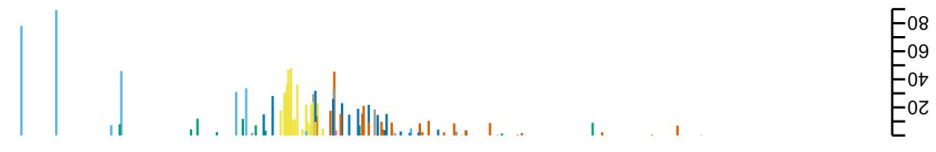

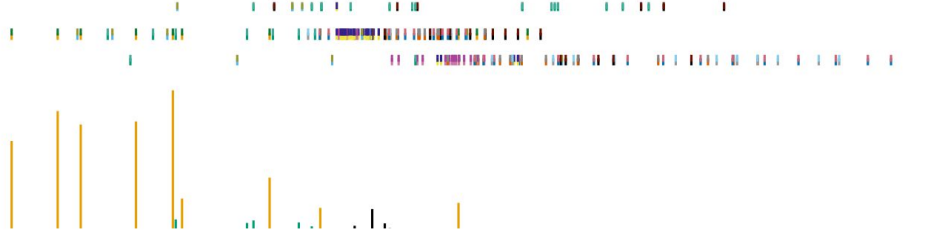

$0_{0.1}^{001}$
$0_{09}^{09}$
$0_{02}^{00}$
$0^{02}$

,$|, \ldots$,$| |. .$

Eoz
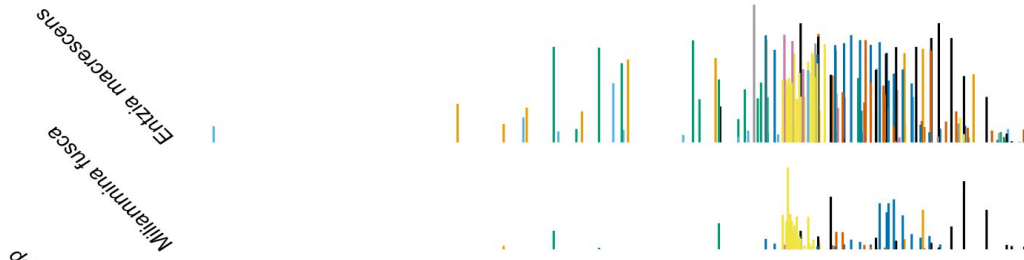

$E_{08}^{00}$

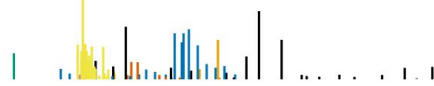

$E_{0+2}^{09}$

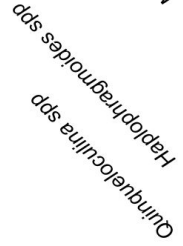

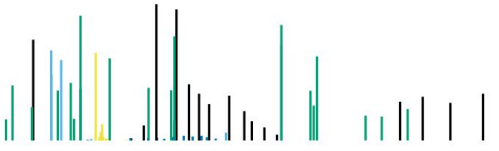

$0_{0.1}^{001}$
0.8
009
0.07
0.02
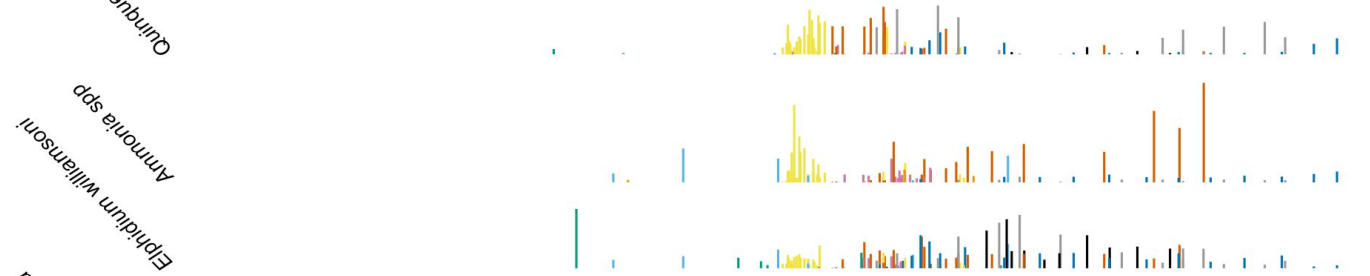

Eor

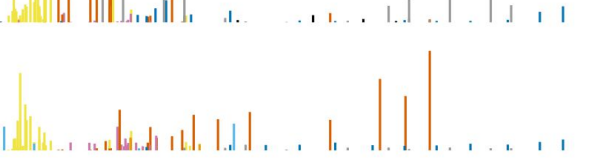

E09

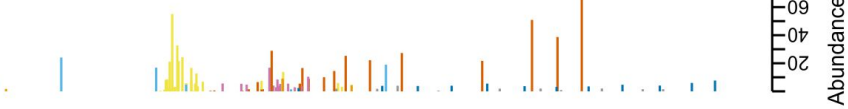

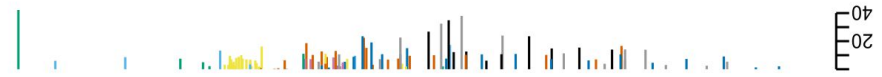

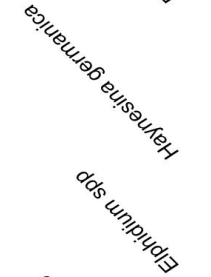

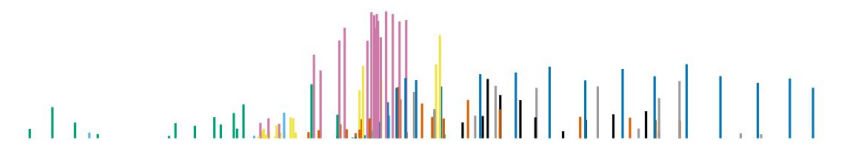
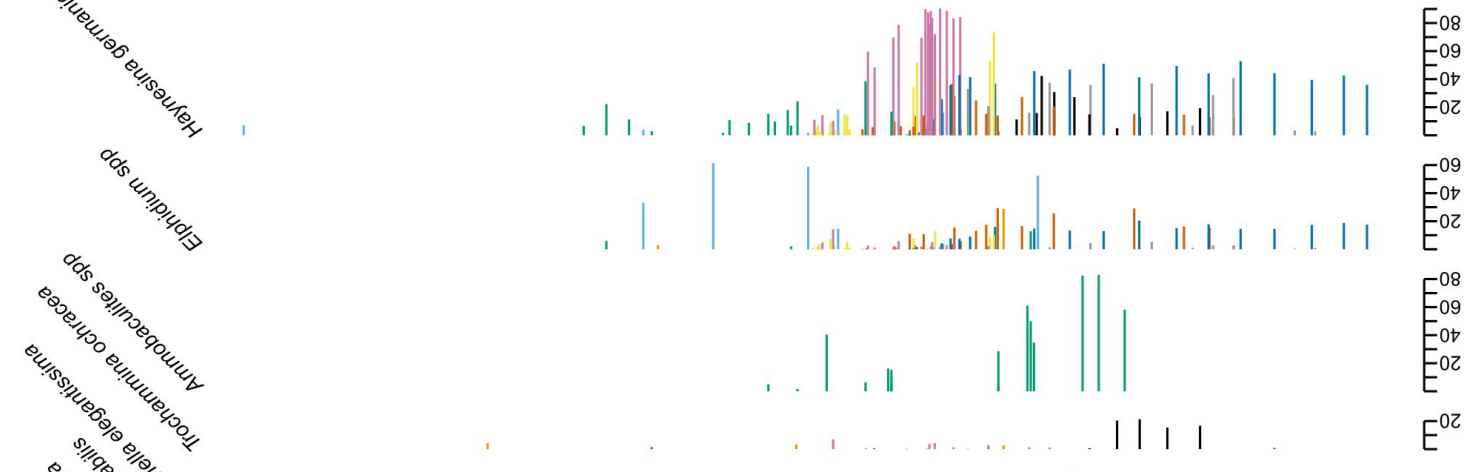

08
09
000
0.2

| | । 1

$E^{0 z}$

年,

|| ||

Eoz
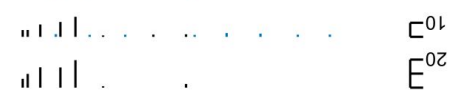

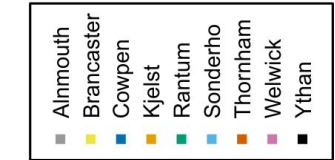

$\ldots,+l_{1}|,+|,, \mid 1, l_{1} \ldots E^{0 z}$

品

(1)

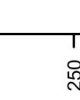

$\left.{ }_{, 1}||_{1}\right|_{1}||_{1} \mid{ }_{1}$

$E_{00}^{09}$ $\check{\sqsubset}^{0+}$ 
Figure 3: The combined North Sea foraminifera data of 218 samples from 9 sites ordered by SWLI value as shown in the first column. Taxa are included that have a maximum abundance $>10 \%$ and occur in more than $10 \%$ of the samples. The bar colour denotes the site corresponding to the legend. The final column shows the groups according to PAM clustering and marked by clusters 1-3.

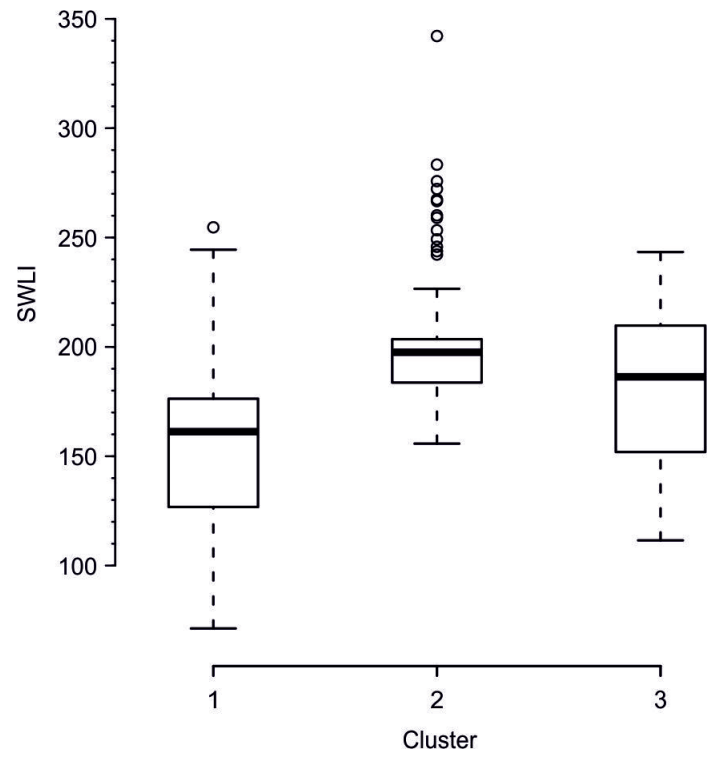

Figure 4: Boxplot of the clusters following PAM clustering of the North Sea training set. The boxplots represent the $2.5,16,50,84647$ and 97.5 percentiles for each cluster. Outliers are represented by the 648 circles.

\subsection{Comparison of training sets and transfer functions}

\subsubsection{Correspondence and cluster analysis} and local training sets is most appropriate for recon- 654 structing sea-level from the core samples shown in Fig. 655 6 we began by plotting DCA, with the core samples 656 passively projected, and PAM, with modern and fos- 657 sil samples combined. The core lithology and fossil 658 foraminifera assemblages are summarised in Fig. 6659 and show salt marsh clays that are dominated by Entzia 660 macrescens and Milliammina fusca abruptly transition- 661 ing to estuarine silts comprising mainly calcareous taxa. 662 DCA results for all of the training sets shown in Fig. 7663 demonstrate an alignment of modern samples with axis 664 1 and a correlation with elevation. The samples are 665 broadly clustered according to elevation, with a sepa- 666 ration between salt-marsh and mudflat samples. There is also a clear distinction between core samples from 667 within the apparent salt-marsh and mudflat zones in all 668 of the plots. The fossil samples appear to show a wider 669 dispersal and closer similarity to modern samples with 670 increasing training set size, whereby the North Sea and 671
In order to assess which of the regional, subregional ${ }^{653}$
West appear to perform well. Although DCA shows that many Ythan samples are occasionally distal from other sites and/or axis 1 in the regional training sets, it is important to observe that they appear to provide closer matches to many fossil samples. This is perhaps not surprising as they come from the same site and that conditions and taxa response show similarities between modern and 8000 years ago. There are clearly still exceptions that may be due to different taxa niches and emphasise the importance of developing regional training sets. The DCA analysis is supported by plotting of the PAM results (Supplementary info Fig. 2) where clusters of modern samples become more clearly grouped by elevation as the training sets reduce in size, although there are overlaps in SWLI values in all. The fossil samples are dispersed between all clusters of each training set. However, the fossil samples become more closely bunched to each other, a measure of the similarity between samples, in the Northwest and Ythan versions and appear most widespread in the West. The correspondence and cluster analysis suggest that the North Sea and West training sets are best suited for reconstructing sea level based on the fossil foraminifera in the Ythan core.

\subsubsection{Modern Analogue Technique}

An assessment of the five closest modern analogues identified by MAT shows that almost all of the closest analogues for every core sample are from sites on the west of the North Sea (Supplementary info Table 2). Only Kjelst from the east provides any of the five closest analogues. The Ythan provides $51 \%$ of the analogues showing that inclusion of the local data is imperative, particularly for the fossil mudflat samples. All sites from the west, with the exception of Thornham, contribute analogues within the closest two, suggesting that in agreement with DCA and cluster analysis, inclusion of the sites in the West training set is required as a minimum to provide acceptable modern analogues to reconstruct sea level from core A7.5.

\subsubsection{Transfer Function performance}

We applied transfer functions using WA with classical deshrinking, WAPLS using the different training sets and LW. Generally performance statistics, shown in Table 2, improve when transfer functions use more 

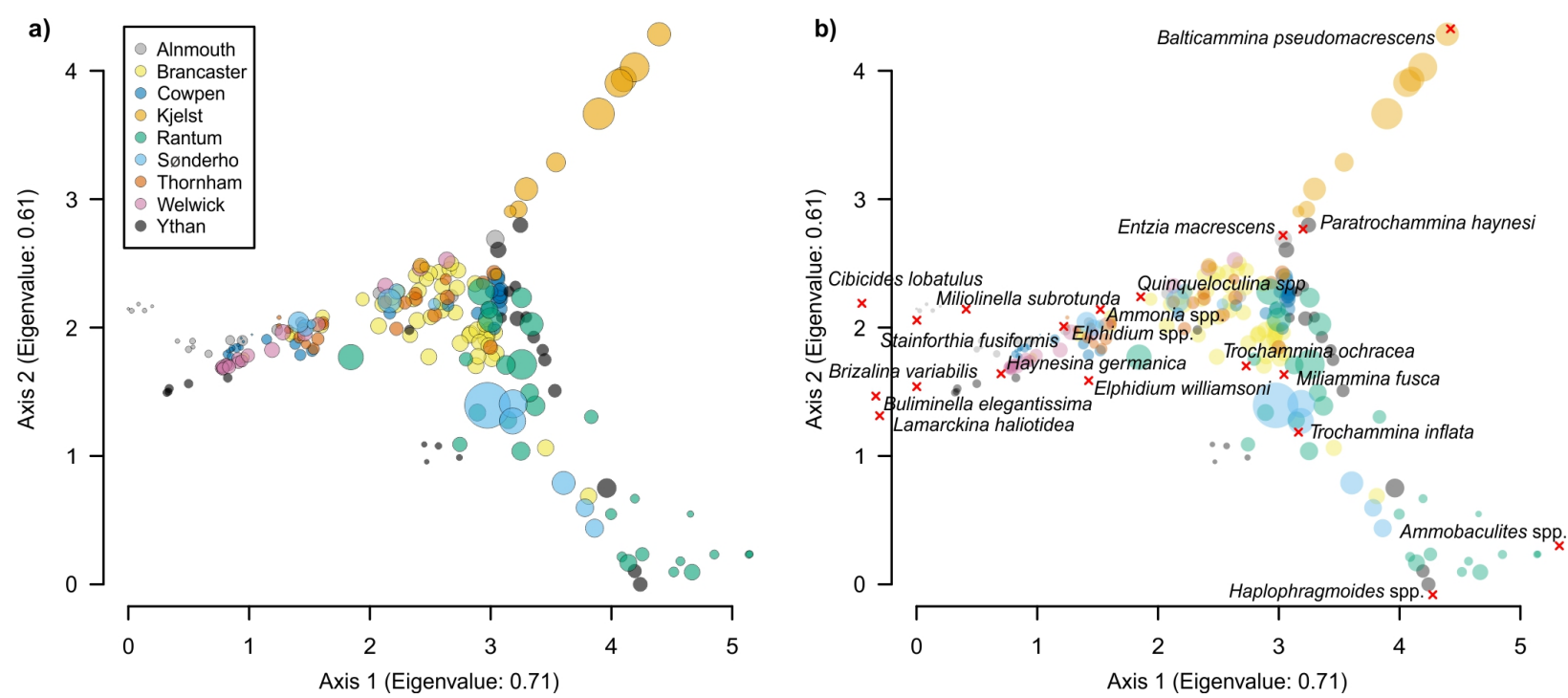

Figure 5: Detrended canonical analysis (DCA) of the North Sea training set. (a) Samples are plotted against elevation and coloured according to site and sized according to SWLI value. (b) Species are added and labelled if the maximum abundance $>10 \%$.

localised training sets in common with other sea-level studies (Horton and Edwards, 2006; Woodroffe and Long, 2010; Barlow et al., 2013). The exceptions are the East transfer functions that perform particularly poorly, and the Northwest that performs worse than the West. The taxa optima and tolerance plots (Fig. 8) demonstrate that the taxa optima within the eastern sites are highly variable and hence the poor performance of the East, which in turn negatively impacts the performance of the North Sea transfer functions. Whilst this provides a wider range of environmental response it comes at the expense of less precision. All of the WA transfer functions have a higher RMSEP and average bias than the corresponding WAPLS models, although they do tend to have a lower maximum bias, and vari- ${ }^{697}$ able $R^{2}$ values. This suggests that classical deshrink- 698 ing performs better at the extreme ends of the gradi- 699 ent, while inverse deshrinking (used in WAPLS models) 700 provides higher accuracy for those in the middle as in- 701 dicated by Birks (1995) and Juggins and Birks (2012). 702 Comparison of the predicted SWLI against observed 703 SWLI (Fig. 9) shows that although better fitting for the 704 most extreme sample may be better in WA transfer func- 705 tions, WAPLS appears to be perform better across the 706 full elevation gradient.
Table 2: Performance statistics for the final transfer functions from each training set. The values given are the cross-validated statistics using leave-one-site-out (LOSO) or bootstrapping (boot). The bootstrapped statistics are converted to metres based on the Ythan tidal regime for core A7.5. Significance is based on 999 trials and the * denotes significant results $(p<0.05)$

\begin{tabular}{|c|c|c|c|c|c|c|c|c|}
\hline \multirow[b]{2}{*}{ Model } & \multirow{2}{*}{$\begin{array}{l}\text { SWLI Ioso } \\
\text { RMSEP }\end{array}$} & \multicolumn{4}{|c|}{ SWLI boot } & \multicolumn{2}{|c|}{ Ythan A7.5 (m) } & \multirow{2}{*}{$\begin{array}{l}\text { Significance } \\
p\end{array}$} \\
\hline & & RMSEP & $R^{2}$ & Av. Bias & Max. Bias & RMSEP & Max. bias & \\
\hline North Sea-WA & 38.59 & 33.88 & 0.55 & 0.09 & 108.93 & 0.56 & 1.80 & 0.12 \\
\hline North Sea-WAPLS-cl & 32.57 & 26.53 & 0.58 & 0.41 & 112.18 & 0.44 & 1.85 & 0.07 \\
\hline North Sea-LW-WAPLS & 34.27 & 24.86 & 0.60 & 1.81 & 118.10 & 0.41 & 1.95 & 0.10 \\
\hline West-WA & 33.51 & 25.63 & 0.61 & -0.04 & 33.33 & 0.42 & 0.55 & 0.10 \\
\hline West-WAPLS-c2 & 34.02 & 19.86 & 0.66 & 0.38 & 45.87 & 0.33 & 0.76 & $0.02^{*}$ \\
\hline West-LW-WAPLS-c2 & $\mathrm{NA}$ & 16.98 & 0.73 & 0.51 & 37.23 & 0.28 & 0.61 & $0.01^{*}$ \\
\hline Northwest-WA & 33.51 & 23.34 & 0.70 & -0.16 & 30.07 & 0.39 & 0.50 & 0.09 \\
\hline Northwest-WAPLS-c2 & 26.8 & 26.77 & 0.52 & 1.52 & 41.31 & 0.44 & 0.68 & 0.06 \\
\hline Ythan-WA & $\mathrm{NA}$ & 22.55 & 0.58 & 1.64 & 41.83 & 0.37 & 0.69 & \\
\hline Ythan-WAPLS-c2 & NA & 17.4 & 0.70 & 1.12 & 14.25 & 0.29 & 0.24 & 0.05 \\
\hline Southwest-WA & 28.32 & 16.99 & 0.56 & -0.25 & 39.04 & 0.28 & 0.64 & $\mathrm{NA}$ \\
\hline Southwest-WAPLS-c2 & 25.57 & 12.46 & 0.67 & -0.18 & 36.87 & 0.21 & 0.61 & $\mathrm{NA}$ \\
\hline East-WA & 45.94 & 37.62 & 0.54 & 1.63 & 71.75 & 0.62 & 1.18 & $\overline{N A}$ \\
\hline East-WAPLS-cl & 44.54 & 40.21 & 0.29 & 7.32 & 66.23 & 0.66 & 1.09 & $\mathrm{NA}$ \\
\hline
\end{tabular}

To assess the independence of samples, either because of training set samples being clustered by sites or the possibility of spatial auto-correlation, we compared cross-validation using LOSO with bootstrapping. Spatial auto-correlation, whereby nearby samples tend to resemble one another more than randomly selected locations, can occur when samples are collected along transects as is common procedure in sea-level research, as opposed to the more ecologically sound methods such as random sampling (Telford and Birks, 2005). If spatial auto-correlation is present it can result in overlyoptimistic RMSEP values and hence misguided model choice (Payne et al., 2012; Kemp and Telford, 2015). LOSO cross-validation removes all samples from one site and predicts the SWLI for them using the remaining sites and repeats the process for each site (Payne et al., 2012). In all regions $\mathrm{RMSEP}_{\text {loso }}$ was greater than 
(a)

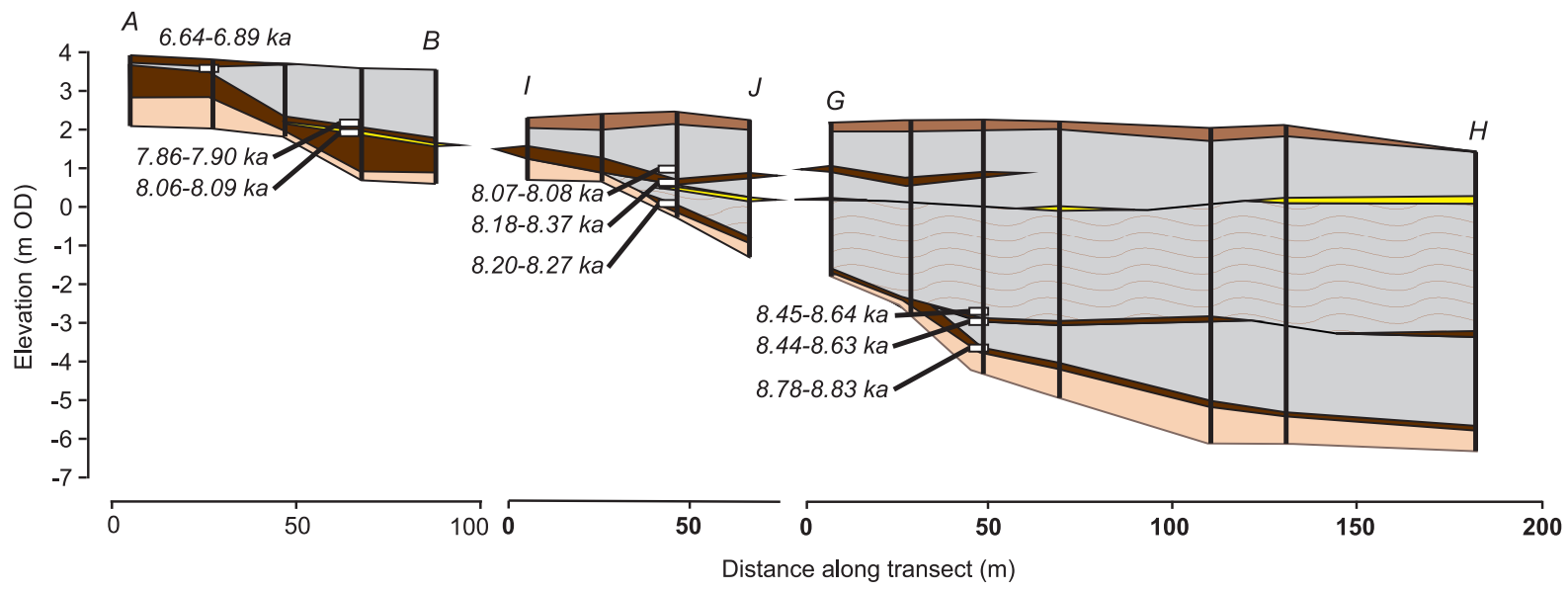

Contemporary salt-marsh

Salt-marsh clays
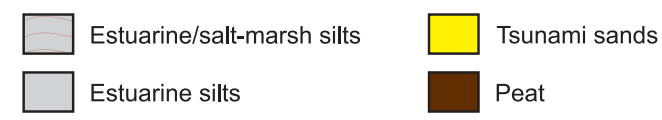

Pre-Holocene deposits

- Radiocarbon dated sample

(b)

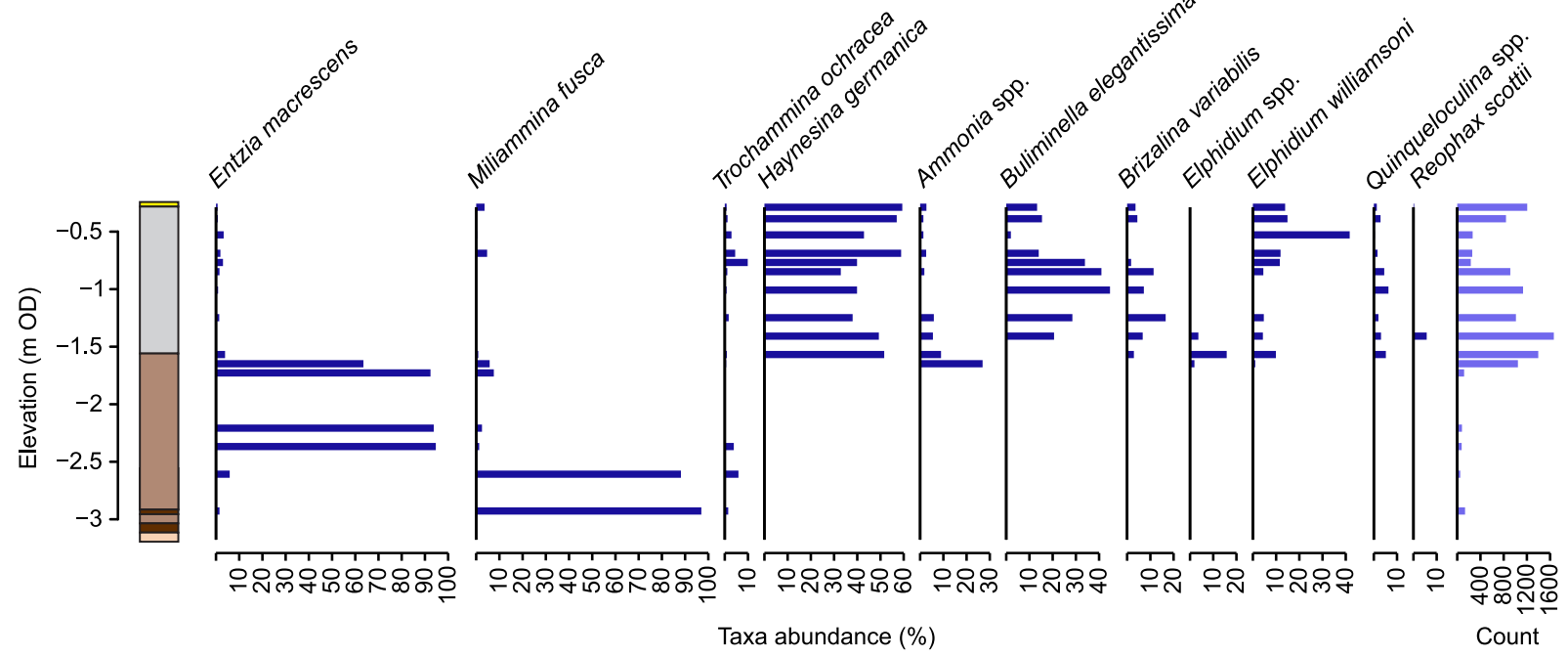

Figure 6: Summary of Ythan palaeo data: a) The lithology and calibrated radiocarbon ages of the transects sampled in the work by Smith et al. (1999) that correspond to Fig. 1. b) Lithology and fossil foraminifera assemblages of core A7.5 from the Ythan Estuary. Foraminifera abundances are given for taxa that have a maximum abundance $>5 \%$.

RMSEP $_{\text {boot }}$ (see Table 2). However, the differences are 724 relatively small suggesting only a limited degree of pos- 725 sible spatial auto-correlation may be present, or alterna- 726 tively the clustering of samples between sites reflects 727 variable local environmental conditions. The inclusion of many sites also minimises the effect of spatial autocorrelation (Legendre and Fortin, 1989; Telford and Birks, 2005) whilst simultaneously making the larger regional transfer functions more robust against environmental changes occurring at a particular site (Barnett et al., 2016). Fig. 10 shows that the sites perform relatively consistently suggesting that one particular site is not being unduly effected and that all sites likely display some environmental variability. 

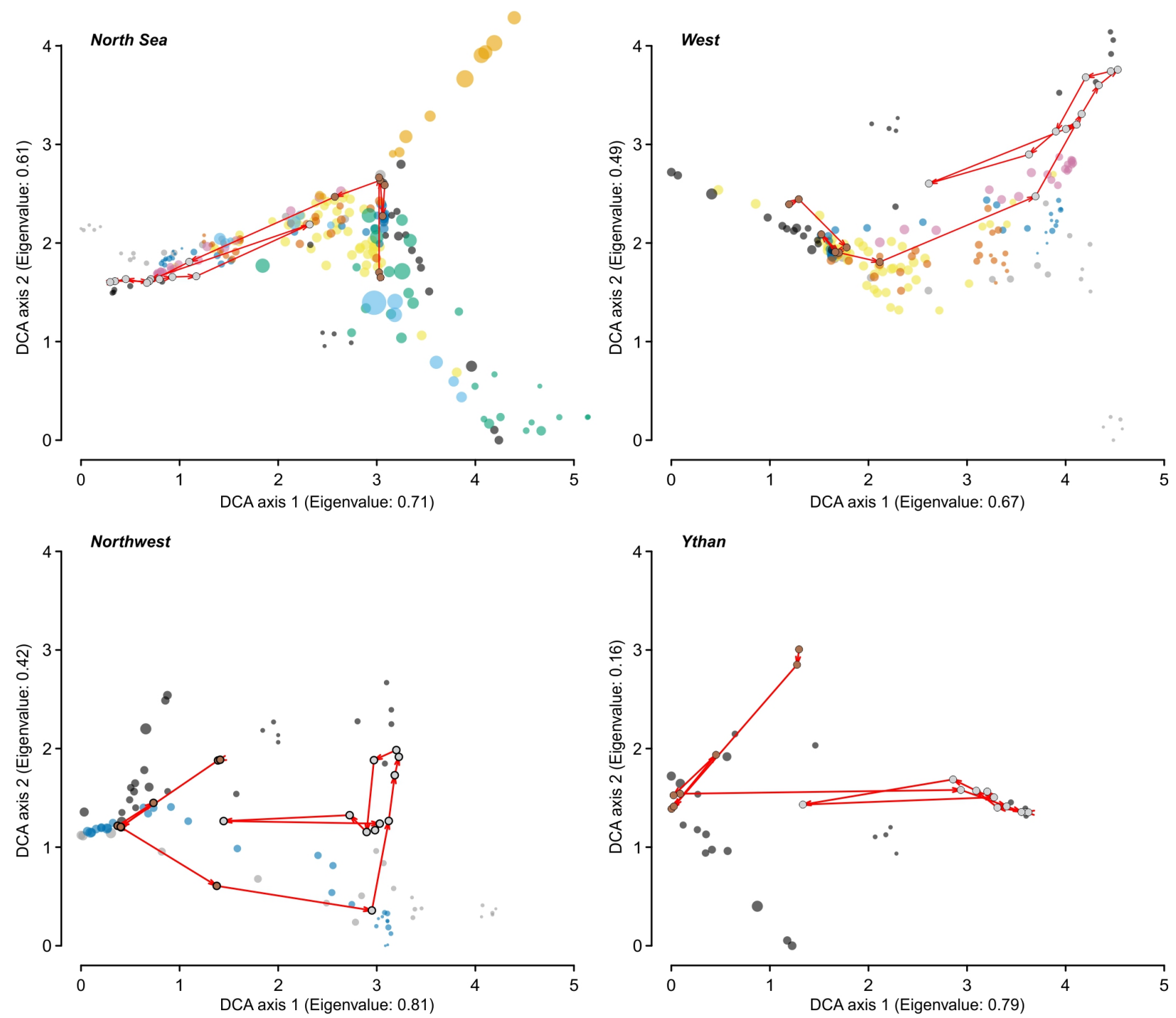

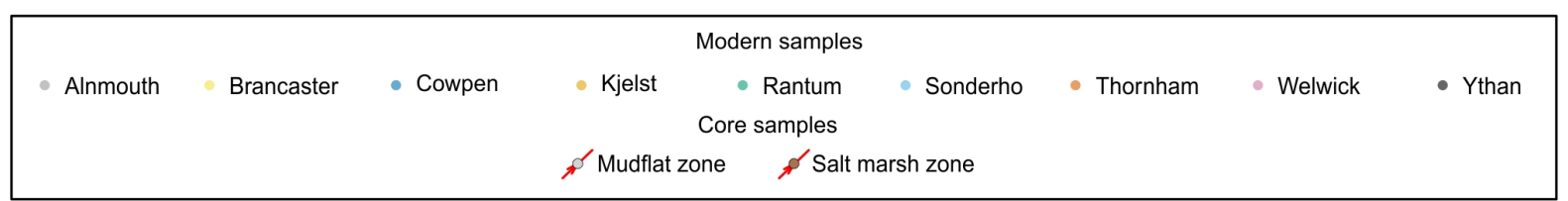

Figure 7: Correspondence analysis of training sets and fossil data showing the four sub-regional training sets and Ythan core samples using detrended correspondence analysis (DCA). The modern samples are coloured by site and the size is scaled by SWLI. The core samples are coloured by the lithology of the core and reflect the stratigraphic succession shown by the red lines with arrows indicating the stratigraphic order.

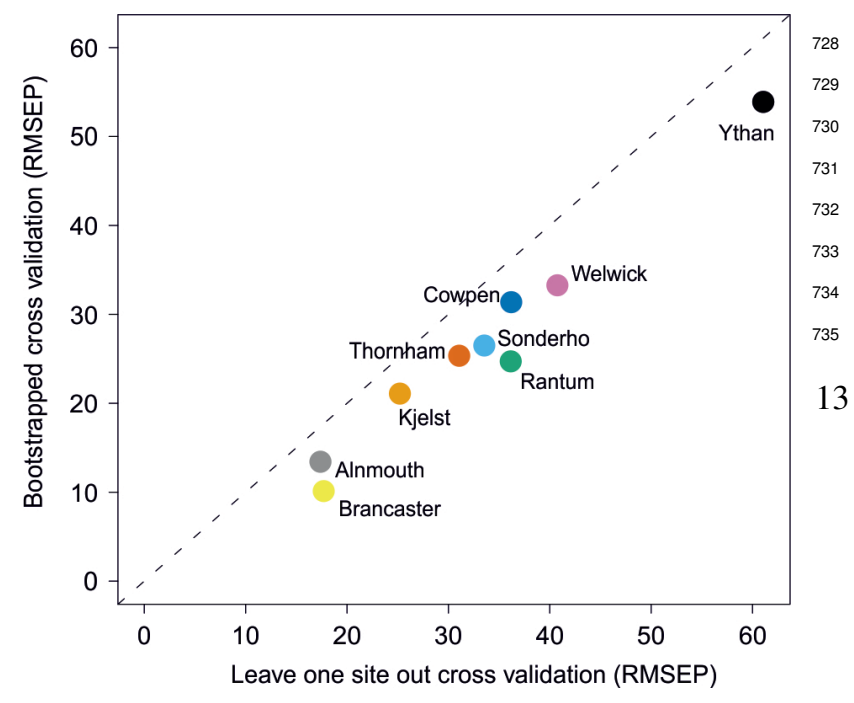

To further assess transfer function performance and understand the effect of deshrinking methods and adding extra complexity in WAPLS with components $>2$, we compared scatterplots of observed versus predicted SWLI and the updated taxa optima (Wright et al., 2011). Fig. 8 shows that when inverse deshrinking (WAPLS component 1) as opposed to classical is applied low elevation taxa are under predicted and high 


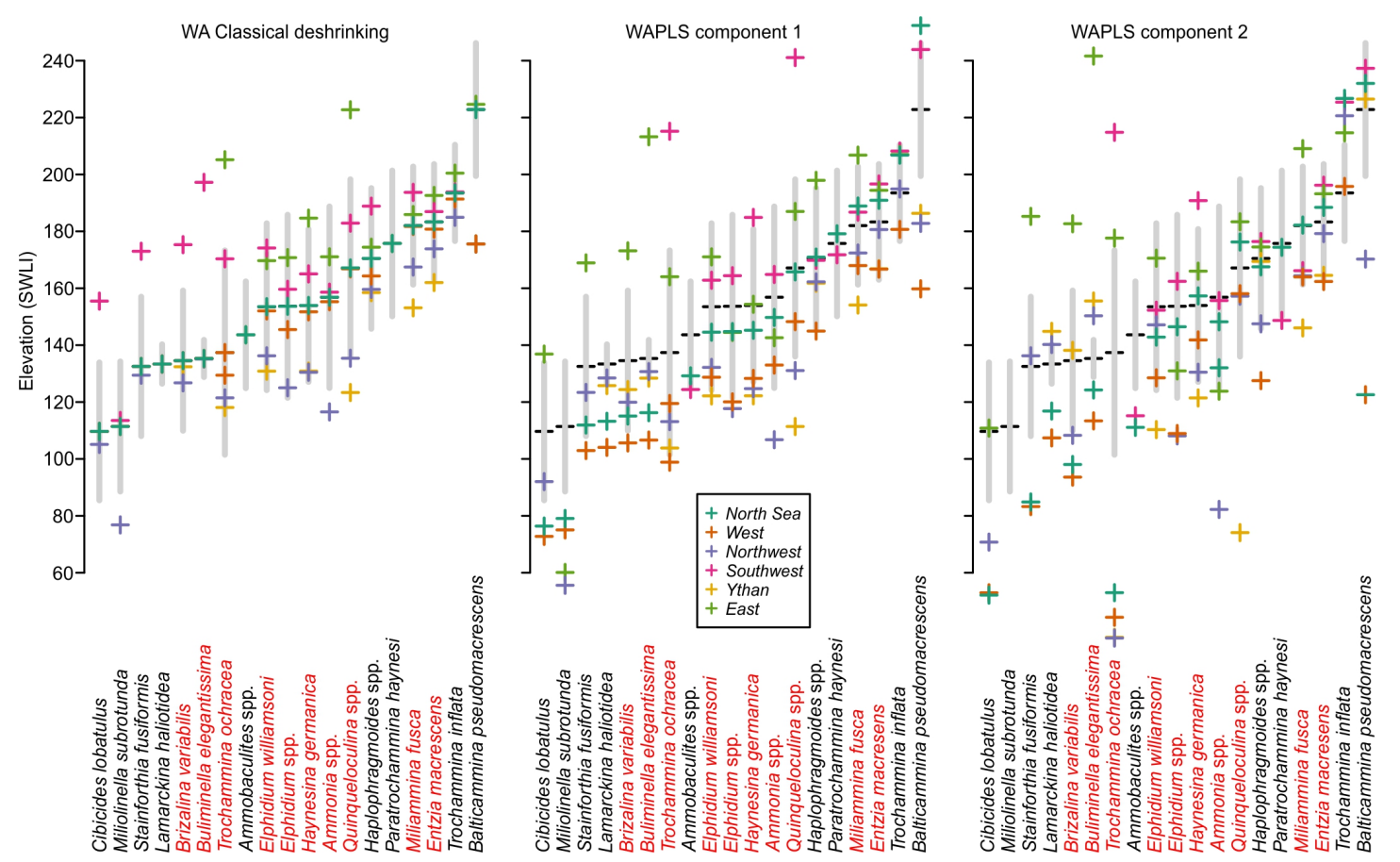

Figure 8: Comparison of the progressive taxa optima updates for the different training sets from WA with classical and inverse (equivalent to WAPLS component 1) to more complex WAPLS transfer functions with multiple components. Taxa tolerances are shown for WA by the grey bar. Taxa are included that have a maximum abundance $>10 \%$ and occur in more than $10 \%$ of the samples. Taxa labels coloured red are taxa that are also found in the Ythan Estuary core (A7.5)
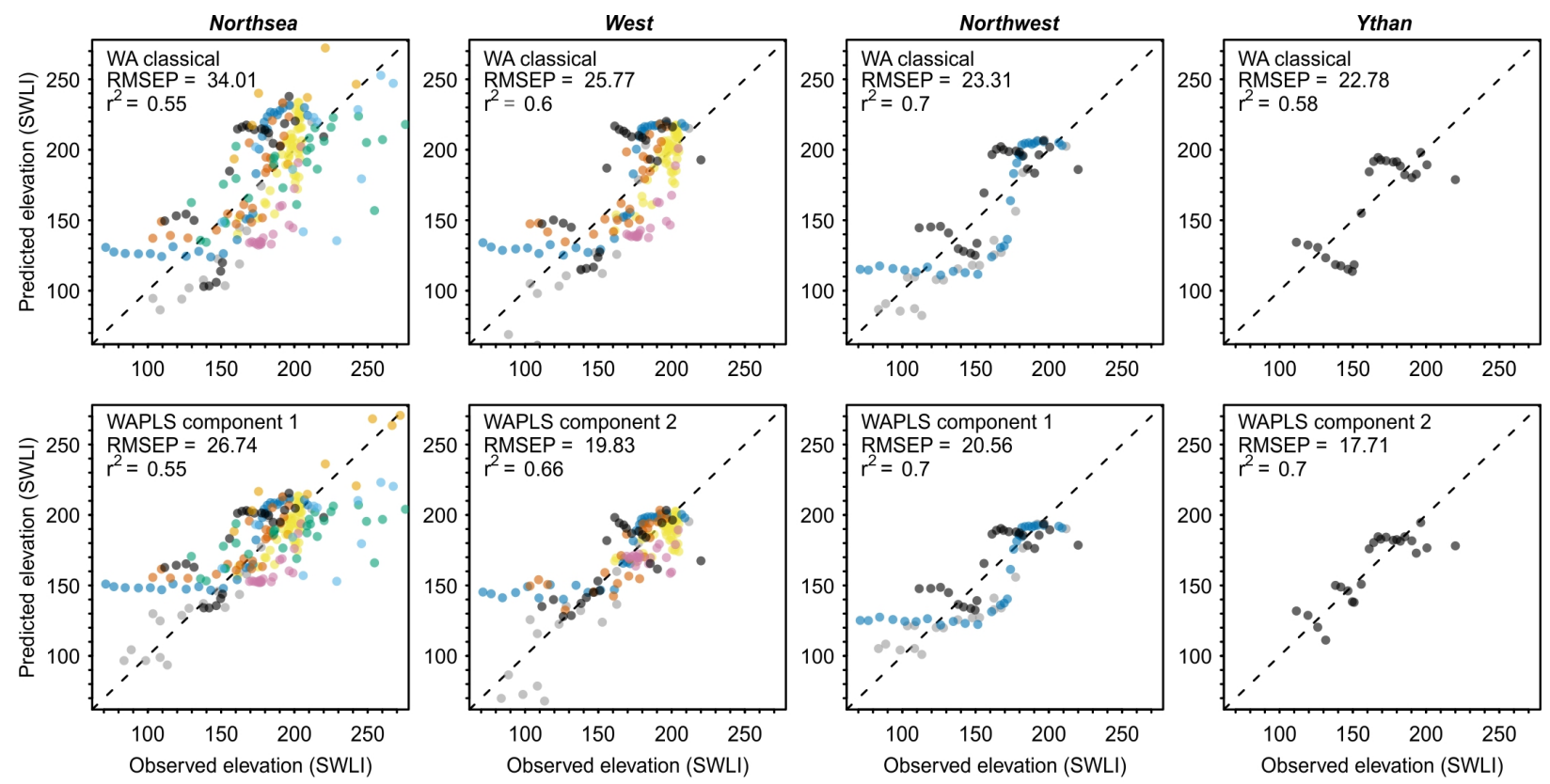

- Alnmouth Brancaster - Cowpen - Kjelst - Rantum - Sonderho - Thornham - Welwick - Ythan

Figure 9: Scatterplots of the observed SWLI against the predicted SWLI for WA classical deshrinking and WAPLS components 1 or 2 depending on which was selected (see text). The samples are coloured according to site as shown in the legend. 
salt-marsh taxa are over predicted, although this is less 787 apparent in Fig. 9 where WAPLS consistently provides 788 more accurate predictions. This is likely because the 789 most abundant taxa tend to have optima towards the 790 centre of the elevation gradient in the training set and 791 are therefore more suitable for inverse deshrinking. Al- 792 though there is noticeable variability between training 793 sets in Fig. 8, the North Sea and West taxa optima 794 are very similar and both appear relatively stable to 795 the effect of adding extra components in WAPLS trans- 796 fer functions. Adding a second component to the West 797 WAPLS transfer function can be seen to produce accu- 798 rate sample predictions shown in Fig. 9 by updating 799 many of the taxa optima (Fig. 8). However, of the taxa 800 that receive major updates only Trochammina ochracea 801 is found in the core and in low abundances and therefore 802 the reconstructions will not be distorted.

Despite the good performance, structure remains in 804 the dataset (see Fig. 9) such that some of the samples 805 found across the elevation gradient of the mudflat (par- 806 ticularly those of Cowpen) have very similar predictions 807 because the samples have very similar taxa abundances. 808 This demonstrates the difficulty in the application of 809 mudflat samples. One option would be to remove these 810 samples but they represent the full environmental gradi- 811 ent of the samples and so we favour retaining all sam- 812 ples but treating predictions with SWLI values $<140{ }_{813}$ with extra caution.

Based on transfer function performance statistics 815 alone, the inclination would be to choose the more lo- 816 calised training sets for sea-level reconstructions for 817 core A7.5. However, incorporating more sites provides ${ }_{818}$ more robustness against the possible effects of clus- 819 tered samples and add additional variability in a taxa- 820 elevation relationship that is likely important for pro- 821 viding analogues for early Holocene foraminifera. Taxa 822 optima are also more stable with a greater number of ${ }_{823}$ sites and suggest these may also be valid.

\subsubsection{Relative sea-level reconstructions}

We applied the preferred WA and WAPLS transfer ${ }_{827}$ functions to reconstruct the palaeo marsh elevation rel- 828 ative to MTL at the Ythan Estuary using the fossil as- ${ }_{829}$ semblages found in core A7.5 (see Fig. 6). All of the re- 830 constructions show a similar pattern of indicative mean- 831 ing change, with periods of rapid decreases (i.e., rela- ${ }_{832}$ tive sea-level rise) at core depths of around $-3 \mathrm{~m}$ and ${ }_{833}$ $-1.6 \mathrm{~m}$ set against a trend of more gradual decrease ( 834 Fig. 11). The reconstructions produced notable differ- 835 ences depending on the training set and whether WA 836 or WAPLS transfer functions were used. The recon- 837 structions using the North Sea and West training sets 838 display very similar patterns to each other, although the precision, as quantified by the sample specific error, increases from North Sea to West. The West model occasionally predicts slightly lower SWLI which is due to the exclusion of the eastern sites that generally have higher taxa optima. The ranges of the Northwest and Ythan reconstructions show divergence from the North Sea and West at differing periods and magnitudes across WA and WAPLS transfer functions. The number of good and close modern analogues as assessed by the MinDC become greater with increased number of sites in the training sets, for example increasing from nine for the Ythan to 24 for the West and North Sea (Fig. 11). The extra samples in the North Sea and West training sets evidently provide better analogues that also drive differing SWLI predictions from the others and hence suggest the Northwest and Ythan produce inaccurate reconstructions.

The ranges of the WA and WAPLS reconstructions show overlap in all cases, although there is a probable difference in the magnitude of both the first and second decrease in indicative meaning. The WA based reconstructions tend to predict lower surface elevations for mudflat samples and higher surface elevations for saltmarsh samples than the WAPLS models. This results in the first period of change being apparently larger in the WAPLS reconstructions compared to the WA, whilst the second is greater in the WA reconstructions. The fossil samples that bound the periods of rapid change appear indicative of mudflats and middle-upper salt marsh with taxa, from towards the gradient ends; predictions of assemblages in these zones are therefore important. Fig. 8 shows that WAPLS appears better at removing the edge-effects than WA even when one component is used (Mohler, 1983) and should thus provide more accurate reconstructions of the fossil mudflat samples. Small changes in species abundances towards the ends of the gradient can substantially alter predictions (Gehrels, 2000). At the upper end this is generally beneficial because of the high precision of high salt-marsh species (Scott and Medioli, 1978; Gehrels, 2000), but can be problematic at lower ends where taxa tolerance can be less precise due to wide apparent niches and taxa sometimes being found at sub-tidal elevations (Berkeley et al., 2007). Lower elevation samples are sometimes removed because of the uncertainty in taxa response to elevation on the mudflats (Edwards and Wright, 2015) especially those that show nonlinearity with elevation (Hamilton and Shennan, 2005). However, despite the difficulties of trying to reconstruct mudflat environments, including the lower elevation samples is required to provide appropriate modern analogues and are there- 
fore justified here. WAPLS transfer functions are con- 888 sequently likely to provide better predictions of both the 889 higher and lower elevation samples.

\subsubsection{Statistical significance of reconstructions}

We tested whether the reconstructions trained on ${ }^{893}$ the different training sets explained more variance in ${ }^{894}$ the core samples than the majority of reconstructions ${ }^{895}$ trained on randomly derived sets of data $(n=999)$ as ${ }^{896}$ proposed by Telford and Birks (2011). The results show ${ }^{897}$ that only the West-WAPLS-c2 produced a statistically ${ }^{898}$ significant reconstruction $(p<0.05)$ (Table 2). The ${ }^{899}$ West-WA and North Sea-WA and North Sea-WAPLS-c1 900 reconstructions perform relatively well and the similar- ${ }^{901}$ ity of reconstructions suggests they these are still valid. ${ }^{902}$ Telford and Birks (2011) argue that palaeoclimatology should not be exempt from interpreting common con- ${ }^{904}$ straints of insignificant results which can be equally applied to sea-level studies, although Kemp et al. (2013) show that some salt-marsh cores do not provide sufficient downcore variability to outperform random data. ${ }^{908}$ In this case the fossil assemblages do provide notable ${ }^{909}$ variety and thus the significant result is somewhat rele- ${ }^{910}$ vant and provides support for the West-WAPLS-c2 trans- ${ }^{911}$ fer function.

\subsection{Training set and transfer function selection}

The challenge of which combination of training set 916 and transfer function model to apply is not a straight- 917 forward decision and may lead to different outcomes as 918 described above in the core reconstruction (seen in Fig. 919 11) and by Barlow et al. (2013). Including all samples 920 from a wider geographic region and a longer elevation 921 gradient captures wider taxa tolerances and provides ${ }_{922}$ more modern analogues. One could therefore argue for 923 including as wide a range as possible. However, the 924 challenge is minimising the range of the reconstructed 925 indicative meanings as much as possible by keeping 926 variability of taxa tolerances to a minimum, whilst still 927 providing an analogue for the past environment that ${ }_{928}$ can produce suitably precise and accurate quantitative 929 reconstructions. We have built on suggested methods 930 for developing transfer functions (Wright et al., 2011; 931 Watcham et al., 2011; Barlow et al., 2013; Kemp and 932 Telford, 2015) with particular consideration for early 933 Holocene sea-level reconstructions to assess this. 934

Assessment of transfer function performance statis- 935 tics alone could lead to the more localised models being 936 preferred due to the lower RMSEP and maximum bias. 937 However, MAT, DCA and PAM silhouette plots show 938 that fossil samples often lack appropriate analogues and 939 similarity with the modern environment in the Ythan and Northwest training sets. The lack of analogues and poor clustering of the Ythan and fossil samples suggest that the likelihood of the foraminifera-elevation relationship at a single site remaining unchanged over a period of thousands of years is unlikely. Even relatively local regional microfossil training sets such as the Northwest here and the West coast of Scotland diatom set (Lawrence et al., 2016) do not necessarily provide suitable modern microfossil analogues and therefore including sites that encompass different environmental conditions in a larger training set appears necessary. A shift in the reconstructed ranges of the reconstructions when moving to the more localised training sets from the West and North Sea training sets is evident further suggesting the reconstructions from the more localised training may lose accuracy. On the basis of missing analogues and lack of similarity we rule out using the Ythan and Northwest training sets for reconstructing the Ythan core.

DCA and cluster analysis suggests that the North Sea and West models both perform well and indeed both have no 'poor' analogues according to MAT. The North Sea training set has more spread in the modern foraminifera tolerances due to the eastern sites. This may simply be adding unnecessary noise, or on the other hand be providing additional analogues and thus better accuracy. However, the foraminifera in the eastern sites appear to be overly affected by the wind-driven water levels that reduces their utility for reconstructing sea level reflected in their higher optima. Using tide loggers as opposed to relying on modelled tidal data may help overcome this issue that will be particularly important at micro-tidal sites. Both West and North Sea training sets do still produce very similar reconstructions for either WA and WAPLS transfer functions suggesting that the small increase in precision in the reconstructions and better predictive ability from the West training set does not come with a loss of consistency. It therefore appears that the modern environment captured by the sites in the West training set provides a suitable analogue for the conditions found at the Ythan Estuary around $8 \mathrm{ka}$ without the noise introduced by eastern sites. We therefore select the West training set for our transfer functions.

The WA and WAPLS transfer functions result in similar reconstructions, with overlapping ranges. The main difference is the prediction of mudflat samples which cause periods of smaller magnitude changes in the WAPLS-derived indicative meanings. WAPLS arguably provides better accuracy for this zone by removing edge effects (Mohler, 1983; Juggins and Birks, 2012) and indeed towards the centre. Furthermore, the 
(a)

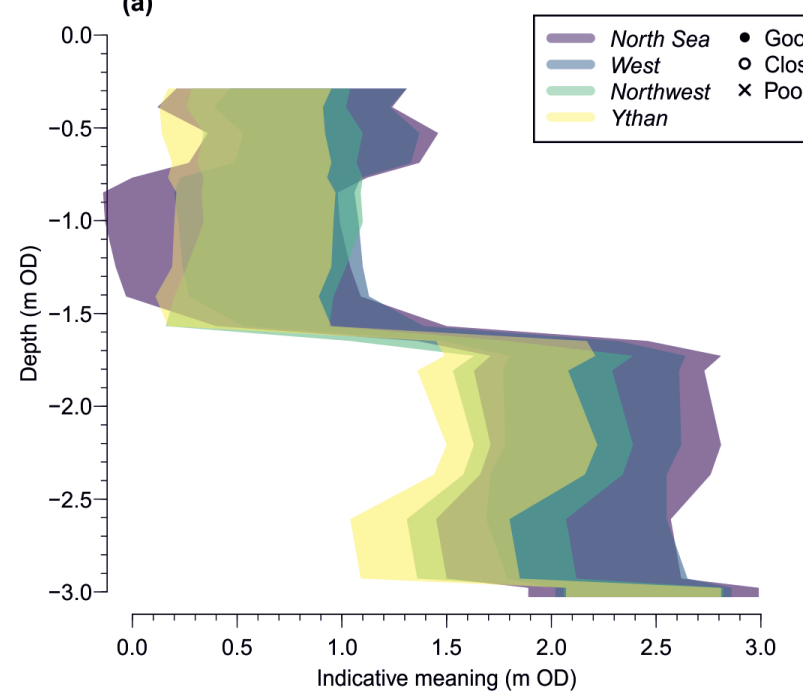

(b)

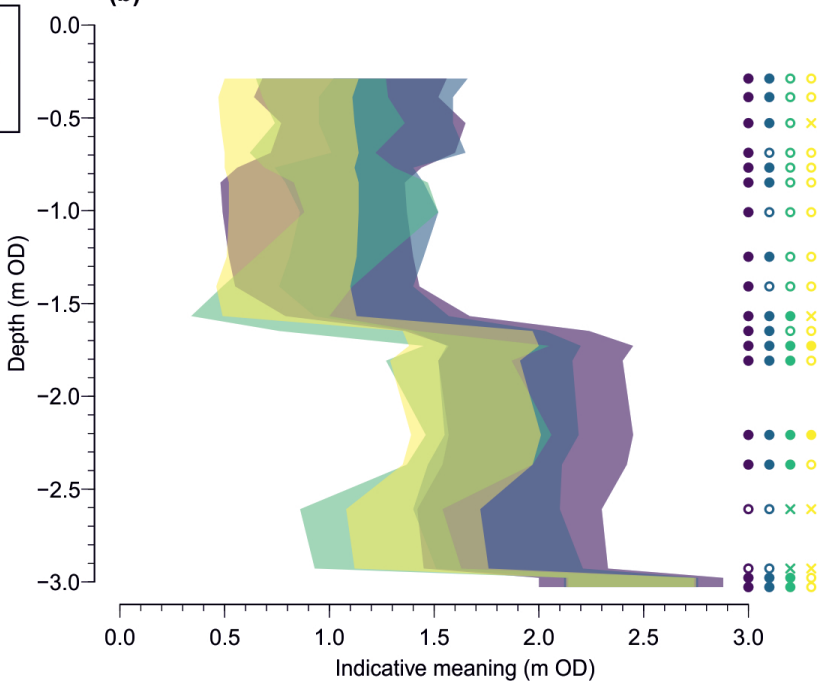

Figure 11: Reconstructed indicative meaning of core A7.5 samples from the different training sets using a) WA and b) WAPLS based transfer functions. 'Good', 'Close' and 'Poor' are measures of the closeness of modern analogues and are taken from the modern analogue technique (MAT) with MinDC values of $<5,5-20$ and $>20^{\text {th }}$ percentiles respectively.

West-WAPLS-c2 is the only transfer function to produce 970 a statistically significant reconstruction. Analysis of the 971 taxa optima updates (Fig. 8) when an extra component 972 is added in the West-WAPLS-c2 transfer function show 973 a number of calcareous taxa from some sites are shifted 974 to well above HAT and so these more complex transfer 975 functions should be treated with caution (Wright et al., 976 2011). However, the taxa found in the fossil assem- 977 blages are not shifted so dramatically and therefore, in 978 this instance, we accept the updates as appropriate for 979 reconstructing the core. Whilst WA and WAPLS both 980 produce similar reconstructions and the decision be- 981 tween the two does not therefore produce significantly ${ }_{982}$ different results we prefer the West-WAPLS-c2 transfer ${ }_{983}$ function owing to the better fitting of predicted SWLI, 984 the reduction in edge-effects compared to WA, the reconstruction being statistically significant and without producing dramatic taxa optima updates of the important foraminifera. The West-WAPLS-c2 transfer function produces a mean sample specific error of $38 \mathrm{~cm}$ for the Ythan fossil samples which can be considered good, particularly in light of the approximately $50 \mathrm{~cm}$ precision obtained in the Lawrence et al. (2016) sea-level reconstruction.

A LW transfer function may circumvent the problem 992 of including a wide range of sites and the associated 993 noise. However, simply running a LW transfer func- 994 tion using the North Sea training set (North Sea-LW- 995 WAPLS) produces inconsistent and unrealistic recon- 996 structions despite the precision being improved. This 997 appears to be because many samples from the eastern sites with SWLI's > 250 are included and have a greater influence than in the full training set. On the other hand, having established the most appropriate sites to include in the modern training set (i.e the West training set) and then running a LW transfer function produces consistent predictions alongside an overall improvement in the precision. Notably, the precision of the tidal-flat samples in the core is unaltered while the predictions of the salt-marsh samples is improved by around $\pm 7 \mathrm{~cm}$. This is consistent with the better predictive ability of saltmarsh foraminifera and demonstrates the benefit of using a LW transfer function, notwithstanding the importance of establishing a suitable training set by way of a thorough assessment in advance.

\section{Conclusions}

We have produced a North Sea training set of modern foraminifera based on eight previously published sites and one new site (Ythan Estuary, Scotland). The foraminifera cover an elevation gradient from the highest elevation at which foraminifera occur to mean tide level. The foraminifera display a relationship with elevation relative to sea level. Foraminifera in marshes in the east (Denmark and Germany) were shown to be very variable, often displaying exceptionally broad elevation ranges that may be due to additional environmental factors such as wind build up that is enhanced by the relatively small tidal range. 
We assessed the effectiveness of a modern regional 1049 training set for reconstructing early Holocene sea level ${ }_{1050}$ at a coastal site in the western North Sea (Ythan Estu- 1051 ary, Scotland) by dividing the data into different sub- 1052 regional training sets and by comparing the results of ${ }_{1053}$ parallel analyses. We applied a step-wise approach that ${ }_{1054}$ considered understanding the core lithology and the fos- 1055 sil samples and understanding of the core alongside the 1056 modern samples in each of the training sets. In summary 1057 we used the following approach, which we also recom- 1058 mend for choosing the most effective transfer function 1059 and training set in similar studies:

1. We qualitatively assessed how appropriate for re- ${ }^{1061}$ constructing sea level each training set was by ap- ${ }^{1062}$ plying detrended correspondence analysis (DCA) ${ }_{1064}^{1063}$ and partitioning around medoids (PAM) clustering. ${ }_{1065}$ The results highlighted that clustering of modern ${ }_{1066}$ samples is apparent and is occasionally driven by ${ }_{1067}^{1066}$ certain taxa, however these are generally rare or ${ }_{1068}^{1067}$ absent in the fossil record and therefore of lesser ${ }^{1068}$ importance in this example. The modern samples from smaller, more localised, training sets show ${ }_{1071}$ a more clearly defined relationship with elevation but often lack similarity with fossil samples. Other ${ }_{1073}^{1072}$ methods of correspondence and cluster analysis are available but some form should be included alongside fossil samples to enable a truer understanding of the suitability of different training sets in each ${ }^{1076}$ context.

2. The modern analogue technique (MAT) was used ${ }_{1079}^{1078}$ as a statistical measure of the similarity between ${ }_{1080}^{1079}$ fossil and modern samples. More localised training sets produced fewer 'good' or 'close' modern ${ }_{1082}$ analogues, while larger training sets produce no 'poor' analogues. This step is almost certainly nec- ${ }_{1084}^{1083}$ essary to validate that the training set is providing ${ }_{1085}^{1084}$ a modern environment analogous to that found at the reconstructed site for the period of interest and should be assessed in conjunction with more qual- ${ }^{1087}$ itative approaches such as in steps 1 and 4 .

3. We ran transfer functions using WA with classical deshrinking and WAPLS components 1 or ${ }^{1090}$ 2 with cross-validation by bootstrapping and by ${ }^{109}$ leave-one-site-out (LOSO) to reconstruct palaeo marsh surface elevation changes from the Ythan ${ }_{1094}$ core. Precision improved in more localised regional models although at a loss of predictive 1095 ability. LOSO cross-validation showed that the 1096 precision of reconstructions are not unduly over- 1097 optimistic and that inter-site variability is present 1098 and likely capture different conditions.
4. We analysed the taxa updates when extra components were added in the WAPLS transfer functions. The taxa are occasionally altered beyond the extent of the sampled elevation range and caution is therefore necessary in choosing these more complex transfer functions. However, comparison with fossil samples showed that the relevant taxa are not fundamentally altered in our example. The updates complement MAT in showing the suitability of analogues. This test is a necessary step and should be carried out along with knowledge of fossil samples.

5. We compared all of the reconstructions to assess the accuracy. All reconstructions showed a similar pattern of surface elevation change, although differences were evident in the uncertainty between WA and WAPLS and when trained on different training sites. As opposed to reconstructions from the more localised training sets, the West models consistently plotted inside the range of the North Sea predictions suggesting that the West models retain the accuracy alongside an improvement in model performance. This procedure provides a good understanding of the consistency and hence the likelihood of producing accurate reconstructions.

6. We ran locally weighted transfer functions using the 50 closest analogues. The West-LW-WAPLS showed an improvement in performance because of improved precision of the salt-marsh sample predictions whilst still enabling the retention of the tidal-flat samples in the training set. This step is evidently worth exploring, particularly when a training set covering such a wide elevation gradient is used, but with the caveat that it should not be taken without an assessment in advance to fully understand the training set.

7. We tested the significance of the reconstructions. Our results showed that only the West-WAPLS-c2 and West-LW-WAPLS-c2 model significantly outperformed transfer functions run on randomly generated data. This test should be ideally included in studies at this stage, although bearing in mind that many cores used in sea-level studies may not have enough variability to outperform random data it may not always be relevant.

Combining data from multiple sites will almost always be necessary to produce early Holocene sea-level reconstructions that are most likely to be accurate. Thus an approach that utilises qualitative and quantitative techniques to assess which training set and transfer 
function is most suitable is also necessary. We have ${ }_{1147}$ shown how our approach can provide an evidence-based 1148 decision that should help ensure a model is chosen that ${ }_{1149}$ has good performance and produces predictions that are 1150 plausibly accurate. We chose the West WAPLS transfer function as the best performing across the full suite of analysis for reconstructing relative sea levels in the ${ }_{115}$ Ythan core. However, the decision may well be different for different cores and regions so we recommend ${ }_{1152}$ that a similar procedure to ours should be followed even ${ }_{1153}$ when using the same training set. Although we focus on ${ }^{1154}$ foraminifera here, the techniques are equally applicable ${ }^{1155}$ to other microfossils such as diatoms and testate amoe- ${ }_{1157}^{1156}$ bae. We advocate that similar step-wise approaches to ${ }_{1158}$ ours are adopted when assessing model choice and that ${ }^{1159}$ accuracy be prioritised over precision.

\section{Acknowledgements}

We are grateful to the editor Richard Jordan and two 1166 anonymous reviewers for their comments that greatly ${ }^{1167}$ improved the early version of the paper. G.R was funded ${ }_{1160}^{1168}$ by a NERC studentship through the ACCE (Adapting 1170 to the Challenges of a Changing Environment) Doctoral ${ }^{1171}$ Training Partnership (Grant No. 2210800). The modern ${ }_{1173}^{1172}$ Ythan samples were collected, prepared and counted as ${ }_{1174}$ part of P.M's University of York BSc thesis: 'Surface 1175 distributions of salt-marsh foraminifera for the Ythan ${ }^{1176}$ estuary, NE Scoltand: an unprecedented modern ana- ${ }_{1178}^{1177}$ logue for Holocene sea-level studies', 2018. We thank ${ }_{1179}$ W McKay and the Scottish Natural Heritage for provid- 1180 ing support and access to the field site. RE, YM and ${ }^{1181}$ RG worked on and provided the previously published ${ }_{1182}^{1182}$ data. We thank the technicians at the Department of En- ${ }_{1184}$ vironment and Geography, University of York, partic- 1185 ularly Maria Gehrels for her assistance with laboratory ${ }^{1186}$ work on the Ythan samples, and the countless other peo- ${ }_{1188}^{1187}$ ple who contributed to the collection and collation of ${ }_{1189}$ the foraminifera data from the existing sites. We also ${ }^{1190}$ acknowledge PALSEA, a working group of the Inter- 1191 national Union for Quaternary Sciences (INQUA) and ${ }_{1193}{ }_{1192}$ Past Global Changes (PAGES), which in turn received ${ }_{1194}$ support from the Swiss Academy of Sciences and the ${ }^{1195}$ Chinese Academy of Sciences.

\section{Data Availability}

Supplementary data to this article can be found online 1202 at https://doi.org/10.1016/j.marmicro.2021. ${ }^{1203}$ 102055. The full North Sea modern foraminifera is ${ }_{1205}^{1204}$ also available on figshare at https://figshare.com/ 1206
authors/Graham_Rush/11546401 along with the R code to carry out the analysis. A vignette for running the code is provided at https://rpubs.com/ GrahamRush\#

\section{References}

Allen, J. R. L. (2000), 'Morphodynamics of Holocene salt marshes: A review sketch from the Atlantic and Southern North Sea coasts of Europe', Quaternary Science Reviews 19(12), 1155-1231.

Avnaim-Katav, S., Gehrels, W. R., Brown, L. N., Fard, E. and MacDonald, G. M. (2017), 'Distributions of salt-marsh foraminifera along the coast of SW California, USA: Implications for sea-level reconstructions', Marine Micropaleontology 131, 25-43.

Barber, D. C., Dyke, A., Hillaire-Marcel, C., Jennings, A. E., Andrews, J. T., Kerwin, M. W., Bilodeau, G., McNeely, R., Southon, J., Morehead, M. D. and Gagnon, J. M. (1999), 'Forcing of the cold event of 8,200 years ago by catastrophic drainage of Laurentide lakes', Nature 400(6742), 344-348.

Barlow, N. L., Shennan, I., Long, A. J., Gehrels, W. R., Saher, M. H., Woodroffe, S. A. and Hillier, C. (2013), 'Salt marshes as late Holocene tide gauges', Global and Planetary Change 106, 90110.

Barnett, R. L., Garneau, M. and Bernatchez, P. (2016), 'Salt-marsh sea-level indicators and transfer function development for the Magdalen Islands in the Gulf of St. Lawrence, Canada', Marine Micropaleontology 122, 13-26.

Bartholdy, A. T., Bartholdy, J. and Kroon, A. (2010), 'Salt marsh stability and patterns of sedimentation across a backbarrier platform', Marine Geology 278(1-4), 31-42.

Bartholdy, J., Christiansen, C. and Kunzendorf, H. (2004), 'Long term variations in backbarrier salt marsh deposition on the Skallingen peninsula - The Danish Wadden Sea', Marine Geology 203(12), 1-21.

Berkeley, A., Perry, C. T., Smithers, S. G., Horton, B. P. and Taylor, K. G. (2007), 'A review of the ecological and taphonomic controls on foraminiferal assemblage development in intertidal environments', Earth-Science Reviews 83(3-4), 205-230.

Birks, H. (1995), Chapter 6: Quantitative palaeoenvironmental reconstructions, in 'Statistical Modelling of Quaternary Science Data'.

Birks, H. J. (1998), 'Numerical tools in palaeolimnology Progress, potentialities, and problems', Journal of Paleolimnology 20(4), 307-332

Birks, H. J. B. (2012), Overview of numerical methods in palaeolimnology, in H. B. Birks, A. F. Lotter, S. Juggins and P. Smol, J, eds, 'Tracking environmental change using lake sediments', Springer, pp. 19-92.

Birks, H. J., Line, J. M., Juggins, S., Stevenson, A. C. and Ter Braak, C. J. (1990), 'Diatoms and $\mathrm{pH}$ reconstruction', Philosophical Transactions - Royal Society of London, B 327(1240), 263-278.

Bondevik, S., Stormo, S. K. and Skjerdal, G. (2012), 'Green mosses date the Storegga tsunami to the chilliest decades of the $8.2 \mathrm{ka}$ cold event', Quaternary Science Reviews 45, 1-6.

Callard, S. L., Gehrels, W. R., Morrison, B. V. and Grenfell, H. R. (2011), 'Suitability of salt-marsh foraminifera as proxy indicators of sea level in Tasmania', Marine Micropaleontology 79, 121-131.

Culver, S. J. and Horton, B. P. (2005), 'Infaunal marsh foraminifera from the outer banks, North Carolina, U.S.A.', The Journal of Foraminiferal Research 35(2), 148-170.

Dawson, A., Bondevik, S. and Teller, J. T. (2011), 'Relative timing of the Storegga submarine slide, methane release, and climate change during the 8.2 ka cold event', Holocene 21(7), 1167-1171. 
de Rijk, S. (1995), 'Salinity control on the distribution of salt marsh 1272 foraminifera (Great Marshes, Massachusetts)', The Journal of 1273 Foraminiferal Research 25(2), 156-166.

Edwards, R. J. and Horton, B. P. (2000), 'Reconstructing relative sea- 1275 level change using UK salt-marsh foraminifera', Marine Geology 1276 169(1-2), 41-56.

Edwards, R. J. and Wright, A. (2015), Foraminifera, in I. Shennan, 1278 A. J. Long and B. P. Horton, eds, 'Handbook of Sea-level Re- 1279 search', John Wiley \& Sons, Ltd, Chichester, chapter 13, pp. 191- 1280 217

Egbert, G. and Erofeeva, L. (2010), 'The OSU TOPEX/Poseidon 1282 Global Inverse Solution TPXO 8 Atlas v. 1 Africa'. 1283

Engelhart, S. E., Peltier, W. R. and Horton, B. P. (2011), 'Holocene 1284 relative sea-level changes and glacial isostatic adjustment of the 1285 US Atlantic coast', Geology 39(8), 751-754.

Gehrels, W. R. (2000), 'Using foraminiferal transfer functions to pro- 1287 duce high-resolution sea-level records from salt-marsh deposits, 1288 Maine, USA', Holocene 10(3), 367-376.

Gehrels, W. R. (2002), Intertidal foraminifera as palaeoenvironmen- 1290 tal indicators, in 'Quaternary environmental micropalaeontology', 1291 Arnold Publishers, pp. 91-114.

Gehrels, W. R., Kirby, J. R., Prokoph, A., Newnham, R. M., Achter- 1293 berg, E. P., Evans, H., Black, S. and Scott, D. B. (2005), 'Onset of 1294 recent rapid sea-level rise in the western Atlantic Ocean', Quater- 1295 nary Science Reviews 24(18-19), 2083-2100.

Gehrels, W. R., Milne, G. A., Kirby, J. R., Patterson, R. T. and Belk- 1297 nap, D. F. (2004), 'Late Holocene sea-level changes and isostatic 1298 crustal movements in Atlantic Canada', Quaternary International 1299 120(1), 79-89.

Gehrels, W. R. and Newman, S. W. G. (2004), 'Salt-marsh 1301 foraminifera in Ho Bugt, western Denmark, and their use as sea- 1302 level indicators', Geografisk Tidsskrift-Danish Journal of Geogra- 1303 phy 104(1), 97-106.

Gehrels, W. R., Roe, H. M. and Charman, D. J. (2001), 'Foraminifera, 1305 testate amoebae and diatoms as sea-level indicators in UK salt- 1306 marshes: A quantitative multiproxy approach', Journal of Quater- 1307 nary Science 16(3), 201-220.

Hamilton, S. and Shennan, I. (2005), 'Late Holocene relative sea-level 1309 changes and the earthquake deformation cycle around upper Cook 1310 Inlet, Alaska', Quaternary Science Reviews 24(12-13), 1479- 1311 1498.

Hawkes, A. D., Horton, B. P., Nelson, A. R. and Hill, D. F. (2010), 1313 'The application of intertidal foraminifera to reconstruct coastal 1314 subsidence during the giant Cascadia earthquake of AD 1700 in 1315 Oregon, USA', Quaternary International 221(1-2), 116-140. 1316

Hayward, B. W., Le Coze, F., Varchard, D., Gross, O. and Gross, O. 1317 (2020), 'World modern foraminifera database'. 1318 URL: https://doi.org/10.14284/305 1319

Hennig, C. (2019), fpc: Flexible Procedures for Clustering. R pack- 1320 age version 2.2-3

Hijma, M. P. and Cohen, K. M. (2010), 'Timing and magnitude of the 1322 sea-level jump preluding the 8200 yr event', Geology 38(3), 275- 1323 278.

Hijma, M. P. and Cohen, K. M. (2019), 'Holocene sea-level database 1325 for the Rhine-Meuse Delta, The Netherlands: Implications for the 1326 pre-8.2 ka sea-level jump', Quaternary Science Reviews 214, 68- 1327 86.

Hill, M. O. and Gauch, H. G. (1980), 'Detrended correspondence 1329 analysis: An improved ordination technique', Vegetatio 42(1- 1330 3), 47-58.

1331

Horton, B. P. and Edwards, R. J. (2006), 'Quantifying Holocene sea- 1332 level change using intertidal foraminifera: lessons from the British 1333 Isles', Cushman Foundation Special Publication 40, 1-97. 1334

Horton, B. P., Edwards, R. J. and Lloyd, J. M. (1999), 'A 1335 foraminiferal-based transfer function: Implications for sea-level 1336 studies', Journal of Foraminiferal Research 29(2), 117-129.

Horton, B. P. and Murray, J. W. (2006), 'Patterns in cumulative increase in live and dead species from foraminiferal time series of Cowpen Marsh, Tees Estuary, UK: Implications for sea-level studies', Marine Micropaleontology 58(4), 287-315.

Horton, B. P., Peltier, W. R., Culver, S. J., Drummond, R., Engelhart, S. E., Kemp, A. C., Mallinson, D., Thieler, E. R., Riggs, S. R., Ames, D. V. and Thomson, K. H. (2009), 'Holocene sealevel changes along the North Carolina Coastline and their implications for glacial isostatic adjustment models', Quaternary Science Reviews 28(17-18), 1725-1736.

Juggins, S. (2017), rioja: Analysis of Quaternary Science Data. R package version 0.9-21.

Juggins, S. and Birks, H. J. B. (2012), Quantitative environmental reconstructions from biological data, in H. B. Birks, A. F. Lotter, S. Juggins and P. Smol, J, eds, 'Tracking Environmental Change Using Lake Sediments. Volume 5: Handling and Numerical Techniques', Springer, pp. 431-494.

Kaufmann, L. and Rousseeuw, P. J. (1990), Finding groups in data: an introduction to cluster analysis, John Wiley, New York.

Kemp, A. C., Horton, B. P. and Culver, S. J. (2009), 'Distribution of modern salt-marsh foraminifera in the Albemarle-Pamlico estuarine system of North Carolina, USA: Implications for sea-level research', Marine Micropaleontology 72(3-4), 222-238.

Kemp, A. C., Horton, B. P., Vann, D. R., Engelhart, S. E., Grand Pre, C. A., Vane, C. H., Nikitina, D. and Anisfeld, S. C. (2012), 'Quantitative vertical zonation of salt-marsh foraminifera for reconstructing former sea level; an example from New Jersey, USA', Quaternary Science Reviews 54, 26-39.

Kemp, A. C. and Telford, R. J. (2015), Transfer functions, in I. Shennan, A. Long and B. Horton, eds, 'Handbook of Sea-level Research', 1 edn, John Wiley \& Sons, Ltd, pp. 470-499.

Kemp, A. C., Telford, R. J., Horton, B. P., Anisfeld, S. C. and Sommerfield, C. K. (2013), 'Reconstructing Holocene sea level using salt-marsh foraminifera and transfer functions: Lessons from New Jersey, USA', Journal of Quaternary Science 28(6), 617-629.

Kemp, A. C., Wright, A. J. and Cahill, N. (2020), 'Enough is enough, or more is more? testing the influence of foraminiferal count size on reconstructions of paleo-marsh elevation', Journal of Foraminiferal Research 50, 266-278.

Lawrence, T., Long, A. J., Gehrels, W. R., Jackson, L. P. and Smith, D. E. (2016), 'Relative sea-level data from southwest Scotland constrain meltwater-driven sea-level jumps prior to the $8.2 \mathrm{kyr} \mathrm{BP}$ event', Quaternary Science Reviews 151, 292-308.

Legendre, P. and Fortin, M. J. (1989), 'Spatial pattern and ecological analysis', Vegetatio 80(2), 107-138.

Leorri, E., Fatela, F., Cearreta, A., Moreno, J., Antunes, C. and Drago, T. (2011), 'Assessing the performance of a foraminiferabased transfer function to estimate sea-level changes in northern Portugal', Quaternary Research 75(1), 278-287.

Li, Y. X., Törnqvist, T. E., Nevitt, J. M. and Kohl, B. (2012), 'Synchronizing a sea-level jump, final Lake Agassiz drainage, and abrupt cooling 8200 years ago', Earth and Planetary Science Letters 315, 41-50.

Mills, H., Kirby, J., Holgate, S. and Plater, A. (2013), 'The distribution of contemporary saltmarsh foraminifera in a macrotidal estuary: an assessment of their viability for sea-level studies', Journal of Ecosystem $\mathcal{G}$ Ecography 3, 1-16.

Mohler, C. L. (1983), 'Effect of sampling pattern on estimation of species distributions along gradients', Vegetatio (54), 97-102.

Müller-Navarra, K., Milker, Y. and Schmiedl, G. (2016), 'Natural and anthropogenic influence on the distribution of salt marsh foraminifera in the Bay of Tümlau, German North Sea', The Journal of Foraminiferal Research 46(1), 61-74.

Müller-Navarra, K., Milker, Y. and Schmiedl, G. (2017), 'Applica- 
bility of transfer functions for relative sea-level reconstructions 1402 in the southern North Sea coastal region based on salt-marsh 1403 foraminifera', Marine Micropaleontology 135, 15-31.

Murray, J. W. (2003), 'Patterns in the cumulative increase in species 1405 from foraminiferal time-series', Marine Micropaleontology 48(1- 1406 2), 1-21.

Murray, J. W. and Bowser, S. S. (2000), 'Mortality, protoplasm de- 1408 cay rate, and reliability of staining techniques to recognize 'living' 1409 foraminifera: a review', The Journal of Foraminiferal Research 1410 30(1), 66-70.

Oksanen, J., Blanchet, F. G., Friendly, M., Kindt, R., Legendre, P., 1412 McGlinn, D., Minchin, P. R., O’Hara, R. B., Simpson, G. L., Soly- 1413 mos, P., Stevens, M. H. H., Szoecs, E. and Wagner, H. (2019), 1414 vegan: Community Ecology Package. R package version 2.5-5. 1415

Payne, R. J., Telford, R. J., Blackford, J. J., Blundell, A., Booth, R. K., 1416 Charman, D. J., Lamentowicz, , Lamentowicz, M., Mitchell, E. A., 1417 Potts, G., Swindles, G. T., Warner, B. G. and Woodland, W. (2012), 1418 'Testing peatland testate amoeba transfer functions: Appropriate 1419 methods for clustered training-sets', Holocene 22(7), 819-825.

Pedersen, J. B. T., Svinth, S. and Bartholdy, J. (2009), 'Holocene evolution of a drowned melt-water valley in the Danish Wadden Sea', Quaternary Research 72(1), 68-79.

Rousseeuw, P. J. (1987), 'Silhouettes: a graphical aid to the interpretation and validation of cluster analysis', Journal of computational and applied mathematics 20, 53-65.

Scott, D. B. and Hermelin, J. O. R. (1993), 'A device for precision splitting of micropaleontological samples in liquid suspension', Journal of Paleontology 67(1), 151-154.

Scott, D. S. and Medioli, F. S. (1978), 'Vertical zonations of marsh foraminifera as accurate indicators of former sea-levels', Nature 272(5653), 528-531.

Smith, D. E., Firth, C. R., Brooks, C. L., Robinson, M. and Collins, P. E. F. (1999), 'Relative sea-level rise during the Main Postglacial Transgression in NE Scotland, UK', Transactions of the Royal Society of Edinburgh-Earth Sciences 90, 1-27.

Stapleton, C. and Pethick, J. (1996), Coastal processes and management of Scottish estuaries-III: The Dee, Don and Ythan Estuaries, Scottish Natural Heritage.

Telford, R. J. and Birks, H. (2011), 'A novel method for assessing the statistical significance of quantitative reconstructions inferred from biotic assemblages', Quaternary Science Reviews 30(9-10), 12721278 .

Telford, R. J. and Birks, H. J. (2005), 'The secret assumption of transfer functions: Problems with spatial autocorrelation in evaluating model performance', Quaternary Science Reviews 24(2021), 2173-2179.

ter Braak, C. J. F. and Barendregt, L. G. (1986), 'Weighted averaging of species indicator values: Its efficiency in environmental calibration', Mathematical Biosciences 78(1), 57-72.

ter Braak, C. J. F. and Juggins, S. (1993), Weighted averaging partial least squares regression (WA-PLS): an improved method for reconstructing environmental variables from species assemblages, in 'Twelfth international diatom symposium', Springer, pp. 485-502.

ter Braak, C. J. F. and Smilauer, P. (2012), 'Canoco reference manual and user's guide: software for ordination, version 5.0'.

UK Hydrographic Office (2016), Admiralty Tide Tables, 2016, Volume 1, United Kingdom and Ireland (Including European channel ports)., United Kingdom Hydrographic Office.

Watcham, E. P., Bentley, M. J., Hodgson, D. A., Roberts, S. J., Fretwell, P. T., Lloyd, J. M., Larter, R. D., Whitehouse, P. L., Leng, M. J., Monien, P. and Moreton, S. G. (2011), 'A new Holocene relative sea level curve for the South Shetland Islands, Antarctica', Quaternary Science Reviews 30(21-22), 3152-3170.

Watcham, E. P., Shennan, I. and Barlow, N. L. M. (2013), 'Scale considerations in using diatoms as indicators of sea-level change: lessons from Alaska', Journal of Quaternary Science 28(2), 165179.

Woodroffe, S. A. (2009), 'Recognising subtidal foraminiferal assemblages: implications for quantitative sea-level reconstructions using a foraminifera-based transfer function', Journal of Quaternary Science 24(3), 215-223.

Woodroffe, S. A. and Long, A. J. (2010), 'Reconstructing recent relative sea-level changes in West Greenland: Local diatom-based transfer functions are superior to regional models', Quaternary International 221(1-2), 91-103.

Wright, A. J., Edwards, R. J. and van de Plassche, O. (2011), 'Reassessing transfer-function performance in sea-level reconstruction based on benthic salt-marsh foraminifera from the Atlantic coast of NE North America', Marine Micropaleontology 81(1-2), 43-62.

Zong, Y. and Horton, B. P. (1999), 'Diatom-based tidal-level transfer functions as an aid in reconstructing Quaternary history of sea-level movements in the UK', Journal of Quaternary Science 14(2), 153-167. 